\title{
CONTAMINANTES EMERGENTES EM MATRIZES AQUÁTICAS DO BRASIL: CENÁRIO ATUAL E ASPECTOS ANALÍTICOS, ECOTOXICOLÓGICOS E REGULATÓRIOS
}

\author{
Cassiana C. Montagner ${ }^{\mathrm{a}, *}$, Cristiane Vidal ${ }^{\mathrm{a}}$ e Raphael D. Acayaba ${ }^{\mathrm{b}}$ \\ anstituto de Química, Universidade Estadual de Campinas, 13083-970 Campinas - SP, Brasil \\ ${ }^{b}$ Faculdade de Tecnologia, Universidade Estadual de Campinas, 13484-332 Limeira - SP, Brasil
}

Recebido em 11/04/2017; aceito em 03/05/2017; publicado na web em 11/07/2017

\begin{abstract}
EMERGING CONTAMINANTS IN AQUATIC MATRICES FROM BRAZIL: CURRENT SCENARIO AND ANALYTICAL, ECOTOXICOLOGICAL AND LEGISLATIONAL ASPECTS. Emerging contaminants occur in parts per trillion or less in aquatic matrices. The effects related to the exposure of aquatic biota and human to them have been identified for different compounds. The knowledge about the concentrations of the exposure is the first step to perform risk assessments. The present work describes a literature review about occurrence in Brazilian aquatic matrices, and a discussion about biological effects, legislation and analytical aspects involving the presence of emerging compounds. The review includes 58 papers published between 1997 and 2016, considering the occurrence of personal care and pharmaceutical compounds, illicit drugs, hormones, pesticides and some other endocrine disruptors compounds in the matrices sewage, surface, ground and drinking waters. The concentrations varied from ng L $\mathrm{L}^{-1}$ to $\mu \mathrm{L} \mathrm{L}^{-1}$, depending on the region and the compound. However, the contamination scenario was aggravated by the combination of poor sanitation status - such as low investment in sewage treatment plants, which led to an expressive contamination of the receiving waters with sewage - and the current goods consumption level, which is similar to that of developed countries. These data provide a good insight into the particular levels of contamination and can be used both for further researches and decision making in the regulation area of public policy.
\end{abstract}

Keywords: emerging contaminants; endocrine disruptors compounds; drinking water; surface water; wastewater.

\section{CONTAMINANTES EMERGENTES}

A temática dos contaminantes emergentes ganhou destaque na década passada e vem sendo abordada em diferentes aspectos por pesquisadores do mundo todo. Tratam-se de centenas de compostos que têm sido detectados nos diferentes compartimentos ambientais (solo, água e ar), sendo eles tanto de origem antrópica (presentes em efluentes domésticos, industriais, hospitalares e aqueles provenientes das atividades agrícola e pecuária), quanto de ocorrência natural (presentes em diferentes espécies de plantas, por exemplo). Estes compostos podem apresentar algum risco ao ecossistema e eles não estão incluídos nos programas de monitoramento de rotina, ou seja, não são legislados. Assim, serão candidatos a uma futura regulamentação dependendo dos resultados obtidos em estudos de ecotoxicidade, efeitos à saúde humana, potencial de bioacumulação, transporte e destino nos diferentes compartimentos ambientais, além da quantidade em que são lançados e, portanto, da concentração no ambiente. Tratam-se de estudos que envolvem diferentes áreas da ciência e que têm sido considerados fundamentais para o esclarecimento dos novos paradigmas relacionados ao estilo de vida moderno. Conhecer os riscos associados à exposição por centenas de novos compostos que ainda não estão contemplados nas legislações vigentes permite antecipar e mitigar sérios danos para as gerações futuras.

Muitos dos efeitos são atribuídos à exposição crônica a esses compostos que ocorrem em concentrações extremamente baixas, principalmente em matrizes aquáticas, na ordem de nanograma a picograma por litro, o que torna ainda mais complexa a análise de avaliação de risco, seja considerando a preservação da vida aquática, dessedentação de animais, recreação ou à saúde humana.

Diversas substâncias têm sido consideradas contaminantes emergentes, tais como: fármacos, compostos usados em produtos

*e-mail: montagner@iqm.unicamp.br de higiene pessoal (ex: protetores solares), hormônios, alquilfenóis e seus derivados, drogas ilícitas, sucralose e outros adoçantes artificiais, pesticidas; subprodutos provenientes de processos de desinfecção de águas (DPB, do inglês, Desinfect by Products); retardantes de chama bromados; compostos perfluorados; siloxanos; benzotriazóis; ácidos naftênicos; percloratos; dioxinas; nanomateriais; líquidos iônicos e microplásticos. Além desses, alguns microorganismos e toxinas de algas também são considerados contaminantes emergentes. ${ }^{1}$

\section{CONTAMINANTES EMERGENTES NO BRASIL}

No Brasil, as pesquisas relacionadas a esses compostos iniciaram-se em 1995 com os trabalhos de Lanchote e colaboradores determinando pesticidas da classe das triazinas no Córrego Espraiado localizado na região de Ribeirão Preto (SP), ${ }^{2}$ e Stumpf e colaboradores ao estudarem a presença de 60 pesticidas na Lagoa de Juturnaíba, na região dos Grandes Lagos no Rio de Janeiro e de sub-produtos de processo de desinfeção de águas na água distribuída à população oriunda da mesma lagoa. ${ }^{3}$ No ano seguinte, Stumpf e colaboradores também estudaram a remoção de fármacos e hormônios em Estações de Tratamento de Esgoto (ETE) e a presença em águas superficiais da bacia do rio Paraíba do Sul no Estado do Rio de Janeiro. ${ }^{4,5}$ Desde então, diversos outros grupos de pesquisa começaram a estudar a presença de contaminantes emergentes nas diferentes matrizes aquáticas (esgoto, águas superficiais e subterrâneas, águas tratada e envasada para consumo humano) do Brasil.

O Brasil apresenta uma ampla área territorial onde se observam cenários conflitantes, tanto socioeconômicos quanto ambientais. De um lado, o Brasil está entre as dez maiores economias do mundo, de acordo com o Fundo Monetário Internacional, com elevado grau de consumo, o que reflete em problemas ambientais que outros países de economias mais desenvolvidas também enfrentam, como a presença de inúmeras novas substancias no ambiente. Por outro lado, ainda 
existe um sério problema de saneamento básico em diversas regiões do país, o que faz com que o Brasil também apresente problemas ambientais típicos de países menos desenvolvidos, como as epidemias de dengue e outras doenças de veiculação hídrica, por exemplo. Somado a isso, trata-se do maior consumidor de pesticidas do mundo com uma extensa área cultivada e cerca de 500.000 toneladas de ingredientes ativos comercializados anualmente, de acordo com o Ministério do Meio Ambiente.

Com isso, é de se esperar que as características regionais de cada Estado, como o uso e ocupação dos solos e o tipo de economia, demandem atenções para classes específicas de contaminantes, o que torna ainda mais complexo um processo de priorização a nível nacional, como o que é feito pela Agência de Proteção Ambiental Americana (USEPA, do inglês, United States Environmental Protection Agency) nos Estados Unidos, por exemplo.

Para se obter um panorama brasileiro do que tem sido estudado sobre a presença dos contaminantes de preocupação emergentes nas matrizes aquáticas, foi feita uma revisão na literatura em revistas indexadas, de acordo com as bases de dados (a) Science Direct www.sciencedirect.com; (b) SciELO - www.scielo.br; e (c) Scopus - http://www.scopus.com; utilizando as palavras-chave: Brasil, ocorrência, esgoto, água superficial, água subterrânea, água tratada, água envasada, cafeína, fármacos, hormônios, drogas, contaminantes emergentes, compostos interferentes endócrinos e pesticidas, tanto em português quanto em inglês publicados até o ano de 2016. Dentro destes critérios, foram considerados nesta revisão 58 artigos publicados, sendo o primeiro em 1997. Na Tabela 1 está apresentado um resumo das concentrações encontradas para as diferentes classes de contaminantes determinadas em cada matriz, sendo que a matriz esgoto foi contemplada em 10 destes 58 trabalhos, a matriz água de abastecimento foi investigada em 16 trabalhos, a matriz água superficial em 44 trabalhos, a matriz água subterrânea em 9 trabalhos e, por fim, houve 1 publicação envolvendo água envasada. No material suplementar estão compilados os resultados dos estudos, incluindo a faixa de concentração dos compostos determinados em cada matriz, além do ano e o Estado onde a amostragem foi realizada e a técnica analítica empregada na quantificação dos contaminantes com os respectivos limites de detecção e quantificação (Tabela 1S). Cada um destes aspectos será abordado com detalhes ao longo desta revisão.

A Figura 1 mostra o número de trabalhos publicados em revistas indexadas por classes de compostos nas principais matrizes ambientais estudadas no Brasil: esgoto, água de abastecimento público e águas superficiais. Os hormônios, seguidos pelos fármacos e produtos de higiene pessoal (PPCP, do inglês, Pharmaceuticals and Personal Care Products), compostos industriais e os pesticidas foram as classes mais estudadas. No caso dos pesticidas, as escolhas dos compostos de interesse seguiram o padrão de consumo de cada região considerando os princípios ativos mais usados nas culturas locais. Para as outras classes, a escolha dos contaminantes seguiram a tendência mundial e acompanharam os compostos considerados prioritários por agências ambientais americana e europeia.

Neste trabalho de revisão não foram considerados os trabalhos de dissertação e tese devido à dificuldade de se obter um levantamento de dados completo a nível nacional, bem como os trabalhos publicados em revistas não indexadas, a fim de se obter um padrão para que os dados apresentados possam ser usados como uma referência do cenário brasileiro atual. No entanto, devido ao crescimento das pesquisas no Brasil que vem ocorrendo nos últimos anos envolvendo esta temática, é de se esperar que os dados de ocorrência que não estão sendo contemplados nesta revisão, se incluídos, poderiam mostrar um cenário de contaminação um pouco diferente do que está apresentado, principalmente com relação as amostras de esgoto, onde o maior interesse da comunidade científica internacional está na eficiência

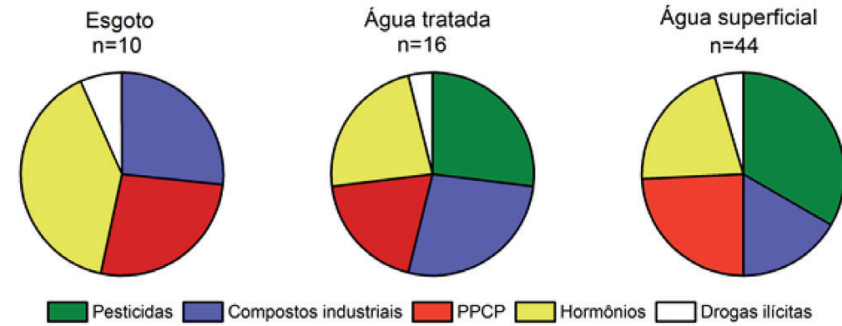

Figura 1. Distribuição das classes dos compostos estudadas nas matrizes aquáticas brasileiras: esgoto*, água tratada e águas superficiais, de acordo com os dados apresentados na Tabela $1 S$, em que $n$ representa o total de trabalhos publicados em revistas indexadas por matriz ambiental, dentro dos critérios estabelecidos. *Matriz esgoto: está indicando os trabalhos publicados sobre esgotos bruto e tratado e sobre efluentes hospitalares do Brasil

de processos de tratamento complementares aos convencionais e na busca por novas alternativas de tratamentos, o que ainda é pouco estudado no Brasil, visto que $99 \%$ das ETE do país operam com tratamento convencional, o qual vem sendo estudado em diversos trabalhos de dissertações e teses.

Em uma visão geográfica sobre o cenário dos contaminantes emergentes no Brasil, foram encontrados dados de ocorrência de diferentes classes de compostos em diferentes matrizes ambientais em 11 dos 26 estados brasileiros e no Distrito Federal. Na Figura 2 estão apresentadas as regiões em que os trabalhos foram realizados e as respectivas matrizes aquáticas estudadas. A região sudeste é a que apresenta o maior número de estudos considerando todas as matrizes com $62 \%$ dos trabalhos publicados, seguida pelas regiões sul (16\%), centro oeste (13\%), nordeste (7\%) e norte (2\%). É possível observar que o foco das pesquisas está nas regiões mais densamente urbanizadas e com elevado índice de industrialização, ou seja, um dos cenários mais críticos quando se considera os impactos da atividade antrópica ao ambiente e, consequentemente, a contaminação pelos compostos de preocupação emergentes. Por outro lado, na região centro oeste, onde o agronegócio é predominante, o estado do Mato Grosso foi o que apresentou a maior quantidade de trabalhos sobre a presença de pesticidas em águas subterrâneas (5 de um total de 7 trabalhos publicados sobre essa matriz), fato que corrobora com o entendimento do uso e ocupação das bacias e a elucidação dos cenários mais preocupantes, uma vez que estamos nos referindo a uma classe de contaminantes que inclui milhares de substâncias que precisam ser priorizadas para então serem estudadas.

Além dos estudos realizados com amostras coletadas localmente nos Estados destacados na Figura 2, houve um trabalho com coleta nacional realizado pelo Instituto Nacional de Ciências e Tecnologias Analíticas Avançadas (INCTAA) que fez uma amostragem ampla sobre a presença de cafeína em amostras de água tratada de 21 capitais estaduais e no Distrito Federal, onde foram coletadas 100 amostras em 61 pontos amostrais. O critério de escolha dos pontos de coleta de água tratada considerou o número de habitantes servidos e o tipo de processo convencional usado no tratamento da água. ${ }^{6,7}$

\section{Matriz: esgotos bruto e tratado}

Sobre o comportamento e o destino dos contaminantes emergentes em estações de tratamento de esgoto do Brasil foram encontrados 10 trabalhos em revistas indexadas que avaliaram a presença e/ou a remoção de hormônios,,$^{5,8-12}$ fármacos, ${ }^{4,12-14}$ bisfenol $\mathrm{A},{ }^{8,9,12,13}$ alquilfenois ${ }^{8}$ e drogas ilícitas, ${ }^{15}$ em cinco estados (Rio de Janeiro, ${ }^{4,5,8}$ São Paulo, ${ }^{9}$ Minas Gerais, ${ }^{12,13}$ Rio Grande do Sul ${ }^{14}$ e Ceará ${ }^{10,11}$ ) e no Distrito Federal. ${ }^{15}$ Os trabalhos buscaram avaliar as eficiências dos tratamentos, as quais variaram entre as diferentes classes de compostos e os 
Tabela 1. Concentrações mínimas e máximas $\left(n \mathrm{~L}^{-1}\right)$ para cada classe de contaminantes nas diferentes matrizes aquáticas brasileiras e as técnicas analíticas utilizadas nas determinações

\begin{tabular}{|c|c|c|c|c|c|c|c|c|c|c|}
\hline \multirow{2}{*}{$\begin{array}{l}\text { Classes/ } \\
\text { Compostos }\end{array}$} & \multicolumn{2}{|c|}{ Esgoto bruto } & \multicolumn{2}{|c|}{ Esgoto tratado } & \multicolumn{2}{|c|}{ Água superficial } & \multicolumn{2}{|c|}{ Água subterrânea } & \multicolumn{2}{|c|}{$\begin{array}{c}\begin{array}{c}\text { Água de abastecimento } \\
\text { público }\end{array} \\
\end{array}$} \\
\hline & $\begin{array}{c}\text { Concentrações } \\
\text { (ng/L) }\end{array}$ & $\begin{array}{l}\text { Técnica } \\
\text { Analítica }\end{array}$ & $\begin{array}{c}\text { Concentrações } \\
\text { (ng/L) }\end{array}$ & $\begin{array}{c}\text { Técnica } \\
\text { Analítica }\end{array}$ & $\begin{array}{c}\text { Concentrações } \\
\text { (ng/L) }\end{array}$ & $\begin{array}{l}\text { Técnica } \\
\text { Analítica }\end{array}$ & $\begin{array}{c}\text { Concentrações } \\
\text { (ng/L) }\end{array}$ & $\begin{array}{c}\text { Técnica } \\
\text { Analítica }\end{array}$ & $\begin{array}{c}\text { Concentrações } \\
\text { (ng/L) }\end{array}$ & $\begin{array}{c}\text { Técnica } \\
\text { Analítica }\end{array}$ \\
\hline Fármacos & $(13,9-3800)$ & $\begin{array}{l}\text { LC-MS/MS } \\
\text { GC-MS }\end{array}$ & $(680-3800)$ & GC-MS & $(0,50-30421)$ & $\begin{array}{c}\text { LC-MS/MS } \\
\text { HPLC-UV } \\
\text { GC-MS }\end{array}$ & & & 18,5 & LC-MS/MS \\
\hline Cafeína & & & & & $(0,29-753500)$ & $\begin{array}{l}\text { LC-MS/MS } \\
\text { HPLC-UV }\end{array}$ & & & $(1,8-5800)$ & $\begin{array}{c}\text { GC-MS } \\
\text { LC-MS/MS }\end{array}$ \\
\hline Hormônios & $(0,56-3180)$ & $\begin{array}{c}\text { LC-MS/MS } \\
\text { GC-MS/MS } \\
\text { GC-MS }\end{array}$ & $(0,09-2080)$ & $\begin{array}{l}\text { LC-MS/MS } \\
\text { GC-MS/MS }\end{array}$ & $(0,31-11130)$ & $\begin{array}{l}\text { LC-MS/MS } \\
\text { HPLC-UV } \\
\text { HPLC-FDL }\end{array}$ & & & $(1,0-340)$ & $\begin{array}{c}\text { GC-MS } \\
\text { LC-MS/MS } \\
\text { HPLC-FDL }\end{array}$ \\
\hline $\begin{array}{l}\text { Produtos de } \\
\text { higiene pessoal }\end{array}$ & & & & & $(2,2-323,5)$ & $\begin{array}{l}\text { LC-MS/MS } \\
\text { GC-MS/MS }\end{array}$ & 137 & GC-MS/MS & $(18-135,5)$ & $\begin{array}{l}\text { LC-MS/MS } \\
\text { GC-MS/MS }\end{array}$ \\
\hline Drogas ilícitas & $(174-9717)$ & LC-MS/MS & & & $(3,0-5896)$ & LC-MS/MS & & & $(6,0-652)$ & LC-MS/MS \\
\hline $\begin{array}{l}\text { Subprodutos } \\
\text { do processo de } \\
\text { desinfecção de } \\
\text { águas }\end{array}$ & & & & & & & & & $(100-41000)$ & GC-ECD \\
\hline Bisfenol A & $(55,7-308,8)$ & LC-MS/MS & $(220-5310)$ & LC-MS/MS & $(2,8-39860)$ & $\begin{array}{l}\text { LC-MS/MS } \\
\text { HPLC-FLD }\end{array}$ & & & $160-3610$ & $\begin{array}{c}\text { GC-MS } \\
\text { LC-MS/MS } \\
\text { HPLC-FLD } \\
\text { GC-MS/MS }\end{array}$ \\
\hline Ftalatos & & & & & $(5,0-33100)$ & $\begin{array}{l}\text { LC-MS/MS } \\
\text { HPLC-UV }\end{array}$ & & & $(24-247)$ & GC-MS/MS \\
\hline Alquilfenóis & & & $(3030-78250)$ & LC-MS/MS & $(1,2-1435)$ & $\begin{array}{l}\text { LC-MS/MS } \\
\text { HPLC-UV }\end{array}$ & & & $(0,04-4)$ & LC-MS/MS \\
\hline $\begin{array}{l}\text { Compostos } \\
\text { perfluorados }\end{array}$ & & & & & & & & & $(0,2-8,8)$ & LC-MS/MS \\
\hline $\begin{array}{l}\text { Bifenilas } \\
\text { policloradas } \\
\text { (PCB) }\end{array}$ & & & & & $(5,0-330)$ & GC-MS/MS & & & & \\
\hline Pesticidas & & & & & $(0,5-23000)$ & $\begin{array}{c}\text { LC-MS/MS } \\
\text { HPLC-UV } \\
\text { HPLD-FLD } \\
\text { HRGC-ECD } \\
\text { GC-MS/MS } \\
\text { GC-MS } \\
\text { GC-NPD }\end{array}$ & $(10-68790)$ & $\begin{array}{c}\text { HPLC-UV } \\
\text { HPLC-FLD } \\
\text { GC-MS/MS } \\
\text { GC-MS } \\
\text { GC-NPD }\end{array}$ & $(0,2-2600)$ & $\begin{array}{c}\text { LC-MS/MS } \\
\text { HPLC-UV } \\
\text { HRGC-ECD } \\
\text { GC-ECD }\end{array}$ \\
\hline
\end{tabular}

GC-ECD = Cromatografia gasosa com detector de captura de elétrons. HRGC-ECD = Cromatografia gasosa de alta resolução com detector de captura de elétrons. GC-NPD = Cromatografia gasosa com detector de nitrogênio-fósforo. GC-MS = Cromatografia gasosa acoplada a espectrometria de massas. GC-MS/MS = Cromatografia gasosa acoplada a espectrometria de massas sequencial. HPLC-UV = Cromatografia líquida de alta eficiência com detector de ultravioleta. Em alguns trabalhos o UV foi obtido pelo Detector de Arranjo de Diodos (DAD). HPLC-FLD = Cromatografia líquida de alta eficiência com detector de fluorescência. LC-MS/MS = Cromatografia líquida acoplada a espectrometria de massas sequencial.

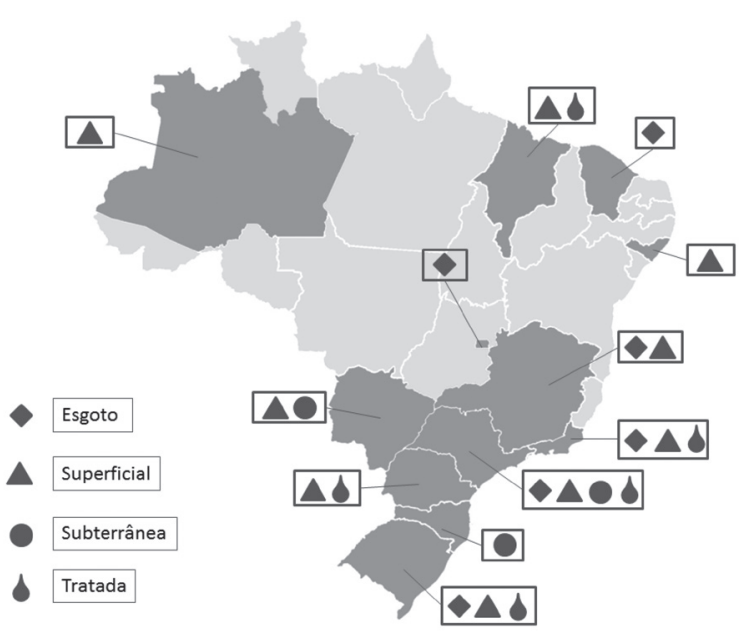

Figura 2. Mapa do Brasil com destaque para as regiões em cinza escuro onde foram estudadas a presença de pelo menos uma classe de contaminantes emergentes nas matrizes: $(\diamond)$ esgoto, ( $\mathbf{\Delta})$ água superficial, (৩) água subterrânea, e $(\bullet)$ água tratada diferentes tipos de tratamento convencional. As concentrações dos contaminantes no esgoto bruto variaram quatro ordens de grandeza, entre 0,56 e $9717 \mathrm{ng} \mathrm{L}^{-1}$, refletindo o padrão de consumo de cada região. ${ }^{4,5,10-13,15}$ No esgoto tratado as concentrações variaram entre 0,09 e $2080 \mathrm{ng} \mathrm{L}^{-1}$ para os hormônios, ${ }^{8,10,11}$ e entre 680 e $78250 \mathrm{ng} \mathrm{L}^{-1}$ para os fármacos ${ }^{4}$ e compostos de origem industrial. ${ }^{8}$ A presença destas substâncias nos diversos efluentes é preocupante, pois eles podem ser considerados a maior fonte de contaminação para o ambiente.

A Figura 3 apresenta as concentrações máximas de cada contaminante quando determinadas nas amostras de esgoto doméstico bruto e tratado acima dos limites de quantificação dos métodos analíticos de acordo com os dados descritos na Tabela 1S. Dentre os 21 compostos estudados nesta matriz, os hormônios foram os mais frequentemente investigados, sendo incluídos em $60 \%$ dos trabalhos brasileiros.

O sistema de saneamento básico no Brasil atende a população usando predominantemente o tratamento convencional tanto para tratar o esgoto quanto para a água que será servida à população. Nas ETE convencionais, as principais etapas de remoção de contaminantes envolvem a eliminação de sólidos grosseiros; a adsorção em sólidos suspensos, sedimentação ou coagulação; biodegradação aeróbica, 


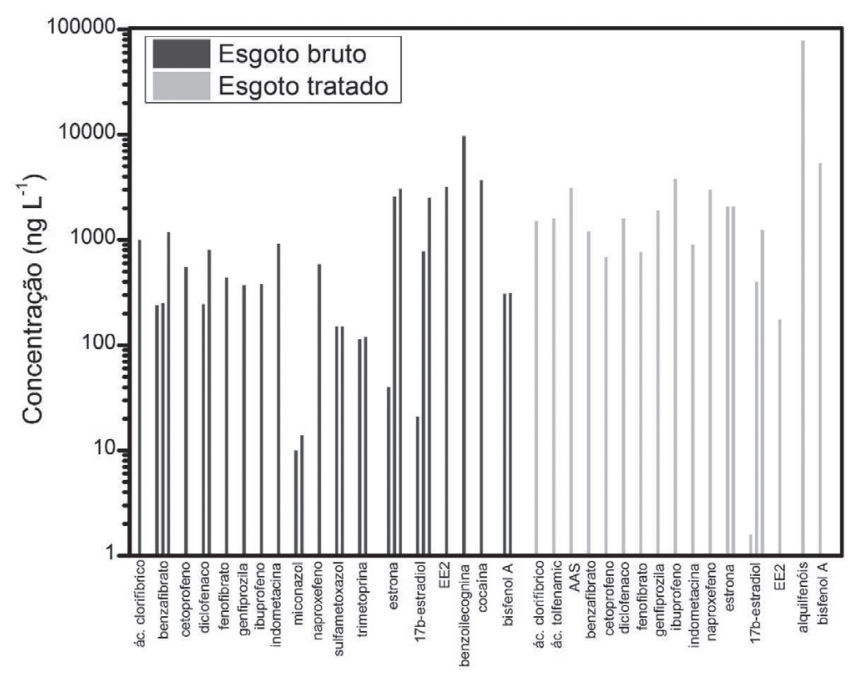

Figura 3. Concentração máxima dos contaminantes emergentes determinados nos esgotos domésticos bruto e tratado no Brasil de acordo com os dados apresentados na Tabela $1 \mathrm{~S}$

por meio de lodo ativado ou filtro biológico, e/ou biodegradação anaeróbica, por meio de reator anaeróbio de fluxo ascendente, RAFA (ou UASB, do inglês Upflow Anaerobic Sludge Blanket); degradação química por processos de hidrólise ou nitrificação e, por fim, a desinfecção. Essas plantas são eficientes para a descontaminação microbiológica e remoção de quantidades elevadas de nutrientes, os maiores responsáveis pelos processos de eutrofização de um corpo d'água. Porém, algumas substâncias não são efetivamente removidas do esgoto após o tratamento, devido a suas propriedades físico-químicas (por exemplo, alta solubilidade) e, assim, permanecem no efluente final. ${ }^{11,16,17}$ Após o tratamento, o efluente líquido é descartado em sistemas de águas naturais, enquanto que o material sólido pode ser utilizado para fertilização e/ou condicionamento de solos agricultáveis, neste caso, os contaminantes presentes no lodo de esgoto aplicado ao solo podem atingir águas naturais por meio do escoamento superficial.

Em 1997, Ternes e colaboradores avaliaram a eficiência de remoção de três estrógenos (estrona (E1), 17ß-estradiol (E2) e $17 \alpha$-etinilestradiol (EE2)) na ETE do município de Penha, no Estado do Rio de Janeiro. Como tratamento utilizou-se clarificação preliminar, tanque aerador ou filtro biológico e uma clarificação final. As concentrações de estrógenos detectados no esgoto bruto foram, em média, $30 \mathrm{ng} \mathrm{L}^{-1}$. Os autores reportaram uma eficiência de remoção destes estrógenos entre $64 \%$, obtida para o EE2 e no efluente do filtro biológico, e 99\%, obtida para o E2 no efluente final, após o lodo ativado). O melhor tratamento foi atribuído ao sistema de lodo ativado. ${ }^{5}$

A ETE da Penha e a ETE de Ilha do Governador no Estado do Rio de Janeiro as quais operam no modo convencional (com biofiltros e/ou sistema de lodos ativados) também foram estudadas em 2010. Ferreira avaliou a remoção de E2, EE2, bisfenol A e alquilfenóis. As concentrações iniciais de E2 foram de 0,56 para a ETE da Penha e 1,24 $\mathrm{ng} \mathrm{L}^{-1}$ para a ETE da Ilha do Governador. Após o tratamento, as concentrações foram determinadas entre 0,09 e $0,34 \mathrm{ng} \mathrm{L}^{-1}$, respectivamente, ou seja, neste caso não houve remoção significativa dos estrógenos. As concentrações de bisfenol A e dos alquilfenois no esgoto bruto e tratado variaram entre 270 e $78250 \mathrm{ng} \mathrm{L}^{-1}$, sendo reportadas remoções de aproximadamente $80 \% .^{8}$

Queiroz e colaboradores avaliaram a eficiência de remoção de hormônios (E2 e EE2), bisfenol A e fármacos (miconazol, sulfametoxazol, trimetoprima, diclofenaco e bezafibrato) em uma ETE da cidade de Belo Horizonte (MG), a qual empregou reatores UASB.
Apesar dos autores considerarem que esse tipo de tratamento seja favorecido pelo baixo custo e pelas condições de temperatura e clima tropical, não foi considerado eficiente na remoção destes contaminantes, cujas as concentrações no esgoto bruto variaram entre um mínimo de $13 \mathrm{ng} \mathrm{L}^{-1}$, obtido para o sulfametoxazol, e um máximo de $300 \mathrm{ng} \mathrm{L}^{-1}$, obtido para o bisfenol A, com diferenças significativas nas frequências de detecção de cada um dos compostos. ${ }^{12,13}$

Pessoa e colaboradores avaliaram a remoção de quatro hormônios (E1, E2, acetato de 17ß-estradiol e EE2) presentes em concentrações de micrograma por litro em cinco ETE no Ceará. As menores eficiências de remoção foram observadas nas plantas que operavam com lagoas de estabilização (44\% de remoção global) e as maiores remoções $(\sim 95 \%)$ foram observadas nas plantas que empregavam sistemas de lodo ativado ou UASB com uma etapa de cloração no final do tratamento. ${ }^{11}$

As concentrações para esgoto bruto e tratado bem como as eficiências de remoção de fármacos e produtos de uso industrial determinadas em plantas de ETE convencionais do Brasil estão coerentes com o que apresentaram Luo e colaboradores em um trabalho de revisão sobre a remoção destes compostos por plantas de tratamento semelhantes de países da Europa, Ásia e dos Estados Unidos. ${ }^{17}$ Há uma grande variação nas faixas de concentração descritas pelos diferentes autores em diferentes países, o que reforça a complexidade dos estudos envolvendo essa matriz, bem como o padrão de consumo de cada população. No entanto, no que diz respeito aos hormônios, enquanto a variação das concentrações no Brasil foi de até três ordens de grandeza, Luo e colaboradores apresentaram, em seu trabalho de revisão, valores que variaram no máximo uma ordem de grandeza em níveis de poucos nanogramas por litro. Para o EE2, por exemplo, as concentrações em esgoto bruto e tratado determinadas em ETE da China, França, Alemanha, Itália, Suécia e Estados Unidos variaram entre 1 e 3 ng L $^{-1},{ }^{17}$ enquanto que no Brasil, há trabalhos que determinaram concentrações entre 0,56 e $3180 \mathrm{ng} \mathrm{L}^{-1}$. 5,10-12

Com relação às drogas ilícitas, a cocaína e o seu metabólito principal, a benzoilecgonina, foram determinadas em concentrações entre 174 e 9717 ng L$^{-1}$ no esgoto bruto de Brasília no ano de 2010. O estudo, aplicado à epidemiologia forense, também revelou uma fonte bastante significativa destes contaminantes para os corpos d'água. ${ }^{15}$

Os efluentes hospitalares também foram alvo de estudos em dois dos 10 trabalhos apresentados na Tabela 1S. Martins e colaboradores determinaram concentrações média de ciprofloxacina no efluente bruto do Hospital da Universidade Federal de Santa Maria (RS) da ordem de $54 \mu \mathrm{g} \mathrm{L}^{-1}$, sendo consideradas até 20000 vezes maiores que aquelas previamente descritas na literatura. Bergamasco e colaboradores determinaram concentrações entre 3 e $162 \mathrm{ng} \mathrm{L}^{-1}$ de bisfenol A, estrona, E2 e EE2 no efluente do Hospital das Clínicas da Universidade Estadual de Campinas (SP).

\section{Matriz: água de abastecimento público}

Em amostras de água tratada do Brasil foram investigados 124 contaminantes de diferentes classes incluindo subprodutos de processos de desinfecção, ${ }^{3}$ hormônios, ${ }^{7,18-23}$ fármacos, ${ }^{24}$ cafeína, ${ }^{7,19,23,24}$ produtos de higiene pessoal, ${ }^{7,19,24,25}$ drogas ilícitas, ${ }^{26}$ compostos de uso industrial ${ }^{7,19,20,22,23,27,28}$ e pesticidas ${ }^{7,19,24,29-31}$ (Figura 1). Deste total de compostos, aproximadamente $45 \%$ foram quantificados em pelo menos uma amostra em concentrações acima dos limites de quantificação dos métodos analíticos empregados. A Figura 4 apresenta as concentrações máximas de compostos quantificadas nas amostras de água de abastecimento público do Brasil, com exceção para os 15 compostos oriundos dos processos de desinfecção de águas cujas concentrações foram determinadas na ordem de microgramas por litro e, na Figura 4, foram representados por DBP. 


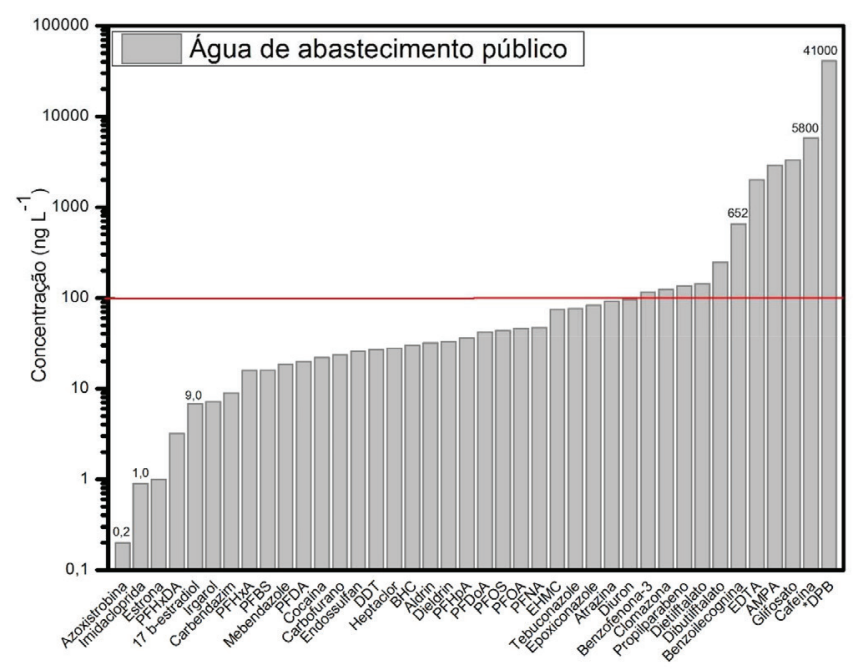

*DBP representa o grupo de 15 compostos formados após o processo de desinfecção de águas estudado por Stumpf e colaboradores (1997)

Figura 4. Concentrações máximas dos contaminantes emergentes determinados em águas de abastecimento público no Brasil de acordo com os dados apresentados na Tabela 1S. A linha vermelha destaca a concentração de $100 \mathrm{ng} \mathrm{L}^{-1}$, a partir da qual pode haver risco ao ser humano ${ }^{32}$

A Cromatografia Líquida acoplada à Espectrometria de Massas sequencial (LC-MS/MS) empregada a partir de 2010 para análises de águas tratadas no Brasil foi usada em 10 dos 16 trabalhos incluídos nesta revisão. Esta tem sido considerada a ferramenta analítica mais adequada para análise de traços em amostras de água tratada devido a elevada detectabilidade e exatidão das medidas. Foram 92 compostos determinados por essa técnica cuja as concentrações variaram entre 0,2 e $652 \mathrm{ng} \mathrm{L}^{-1}$ para os 27 contaminantes quantificados e, entre 1,8 e $5800 \mathrm{ng} \mathrm{L}^{-1}$ para a cafeína. ${ }^{7,19,24}$ Os estudos envolvendo esta matriz são os mais recentes dentre as matrizes aquáticas e foram impulsionados com os avanços das tecnologias analíticas desde o preparo de amostras até a parte instrumental.

Além destes trabalhos, Delmonico e colaboradores determinaram glifosato e ácido aminometilfosfônico (AMPA) em concentrações entre 2100 e 3300 ng L-1 empregando Cromatografia Líquida de Alta Eficiência acoplada ao detector de ultravioleta (HPLC-UV) em amostras de água tratada oriundas do Rio Pirapó em Maringá (PR). ${ }^{31}$ Silva e colaboradores determinaram cinco compostos orgânicos usados em protetores solares dentre os quais, quantificaram benzofenona-3 (18 $\left.115 \mathrm{ng} \mathrm{L}^{-1}\right)$ e metoxicinamato de etilhexila $\left(57-75 \mathrm{ng} \mathrm{L}^{-1}\right)$ em amostras de água tratada coletadas em cidades do interior do estado de São Paulo empregando Cromatografia Gasosa acoplada à Espectrometria de Massas sequencial (GC-MS/MS). ${ }^{25}$ Rissato e colaboradores determinaram 6 pesticidas organoclorados (BHC, aldrim, dieldrin, DDT, endossulfan e heptaclor) em amostras de água tratada da cidade de Bauru (SP) em concentrações que variaram entre 8 e $33 \mathrm{ng} \mathrm{L}^{-1}$ utilizando cromatografia gasosa de alta resolução com detector de captura de elétrons (HRGC-ECD), o qual apresenta detectabilidade adequada à análise de resíduos de compostos voláteis ou semi-voláteis, como são esses analitos de interesse. ${ }^{30} \mathrm{E}$, finalmente, Stumpf e colaboradores, em seu trabalho pioneiro para o Brasil, determinaram 15 DBP incluindo compostos neutros e ácidos em concentrações entre $100 \mathrm{e}$ $41000 \mathrm{ng} \mathrm{L}^{-1}$ empregando GC-ECD, e determinou EDTA em concentrações de $2000 \mathrm{ng} \mathrm{L}^{-1}$ empregando cromatografia gasosa com detector de nitrogênio-fósforo (GC-NPD) em amostras de água tratada oriunda da Lagoa de Juturnaíba na Região dos Lagos (RJ). ${ }^{3}$

Dos 16 trabalhos descritos na literatura para água tratada no Brasil, 10 são provenientes do Estado de São Paulo, ${ }^{18-21,23,25-27,29,30} 2$ são do Rio Grande do Sul, ${ }^{24,28} 1$ do Paraná, ${ }^{31} 1$ do Rio de Janeiro ${ }^{3}$ e 1 do Maranhão, ${ }^{22}$ (Figura 2) além do trabalho de Machado e colaboradores que fez uma amostragem em 21 capitais estaduais e no Distrito Federal. ${ }^{7}$ Neste trabalho, a cafeína foi detectada em $93 \%$ das amostras e as concentrações variaram entre 1,8 e $2769 \mathrm{ng} \mathrm{L}^{-1}$. Para as capitais onde se encontrou a maior concentração de cafeína (São Paulo, Porto Alegre e Belo Horizonte), os mananciais também foram amostrados e as concentrações de cafeína variaram entre 40 e $19000 \mathrm{ng} \mathrm{L}^{-1}$, nas quais também foram detectados o herbicida atrazina e o bisfenol A. Outros compostos de preocupação emergentes foram investigados nestas amostras de águas tratadas sendo, fenolftaleína, triclosan e atrazina detectados em pelo menos uma amostra. A atrazina foi determinada em todo o território nacional, com uma frequência de detecção de $75 \%$ e concentração média nas capitais que variou de 2 a $15 \mathrm{ng} \mathrm{L}^{-1}$, cerca de 1000 vezes menor que o Valor Máximo Permitido (VMP) pela Portaria do Ministério da Saúde 2914/2011, que trata sobre a potabilidade. ${ }^{7}$ Apesar de regulamentada, a atrazina está incluída dentre os contaminantes de preocupação emergentes devido ao seu potencial estrogênico, o qual tem sido melhor elucidado nesta última década e, portanto, não foi contemplado nos cálculos dos VMP vigentes atualmente.

O Institute of Environment and Health (IEH) da Cranfield University no Reino Unido publicou uma revisão dos dados mais recentes sobre as implicações da presença de compostos interferentes endócrinos em água tratada (Final Report DWI:70/2/266). Para tal, tiveram como base 509 artigos e 325 diferentes compostos que foram priorizados, o que gerou uma lista com 159 substancias, para as quais os riscos foram avaliados usando dados de ocorrência ou modelos matemáticos capazes de prever as concentrações após o tratamento considerando as características físico-químicas dos compostos e o tipo de tratamento empregado nas estações de tratamento de água (ETA). Os perfis de perigo foram desenvolvidos para caracterizar a natureza de qualquer risco para a saúde humana relacionado ao consumo de água potável para as substâncias determinadas em concentrações maiores que $100 \mathrm{ng} \mathrm{L}^{-1}$, considerada pelos autores como o pior cenário. ${ }^{32} \mathrm{~A}$ Figura 4 mostra que houve compostos interferentes endócrinos quantificados acima desta concentração nas amostras de água tratada do Brasil. A temática dos interferentes endócrinos será discutida mais adiante nesta revisão.

Nas ETA o tratamento convencional utiliza processos físico-químicos para tornar a água potável, ou seja, para o Brasil, a água que está sendo servida à população deve estar em conformidade com os parâmetros descritos na Portaria do Ministério da Saúde MS 2.914/2011. A etapa de clarificação é feita com floculadores, decantadores e filtros; a desinfecção é feita usando cloradores e aminoadores a depender do processo que está sendo aplicado na planta e as características do manancial e, finalmente o polimento que consiste no ajuste de $\mathrm{pH}$, correção do cloro residual e a fluoretação (que é um aditivo usado no Brasil para evitar a incidência de cáries na população). Um panorama do sistema de abastecimento de água em diversas capitais do país é descrito por INCTAA. ${ }^{6}$

Assim como nas ETE, os processos convencionais de tratamento nas ETA não são eficientes para a eliminação de inúmeros contaminantes orgânicos, devido principalmente a natureza polar de muitos deles. ${ }^{33-35}$ Alguns trabalhos evidenciam que a remoção de interferentes endócrinos nas ETA e ETE também depende tanto das características intrínsecas de cada composto, quanto dos métodos de tratamento. ${ }^{17,34,36,37} \mathrm{O}$ caráter hidrofóbico de alguns contaminantes favorece reações de adsorção ao material particulado em suspensão e, portanto, as técnicas de separação mecânicas como a sedimentação ou a floculação, são capazes de removê-los da água, enriquecendo assim, o lodo. Porém, muitos contaminantes emergentes ainda estão presentes nos efluentes finais que são lançados nos corpos d'água 
pelas ETE operando com pouca eficiência de tratamento, bem como na água tratada distribuída a população a qual é oriunda de mananciais já comprometidos. ${ }^{37}$

Westerhoff e colaboradores demonstraram que métodos convencionais de tratamento promovem a remoção de menos de $25 \%$ da concentração da maioria dos interferentes endócrinos e, a presença de uma etapa de cloração, muito comum para desinfecção de águas no Brasil, promove uma redução de 20 a $90 \%$ nos níveis de concentração, dependendo das características de cada composto. ${ }^{36}$ No entanto, o problema da cloração é a potencialização da formação de inúmeros subprodutos que podem ser consideravelmente mais tóxicos que as moléculas originais..$^{1,3,38}$

Processos de tratamento terciários como ozonização, processos oxidativos avançados (UV, $\mathrm{UV} / \mathrm{H}_{2} \mathrm{O}_{2}$, fotocatálise homogênea e heterogênea, etc.), adsorção em carvão ativado, filtração em membranas (microfiltração, ultrafiltração e nanofiltração) e osmose reversa têm sido aplicados em ETA e ETE como métodos complementares de remoção de contaminantes em inúmeros países. ${ }^{17,36}$ De maneira geral, cada tipo de tratamento possui vantagens e desvantagens que devem ser consideradas pelas estações no momento de se implementar um tratamento terciário na planta. É importante projetar custos, espaço físico, além de se conhecer o tipo de efluente que se deseja tratar, seja esgoto bruto, efluente industrial ou manancial, para que os resultados atendam aos objetivos de cada tratamento.

$\mathrm{O}$ reuso indireto de água se tornou comum nos grandes centros urbanos, onde uma cidade capta água de um manancial superficial e lança seu efluente à jusante do corpo hídrico e, após alguns quilômetros, outra cidade utiliza o mesmo corpo receptor para abastecimento público e assim sucessivamente, deteriorando a qualidade do manancial ao longo do seu curso. Tal prática é realizada no Brasil sem qualquer planejamento urbano, o que é ainda mais agravado com o aporte de grandes quantidades de esgoto bruto nos mananciais, dificultando ainda mais o tratamento da água que é distribuída à população. Um sistema de saneamento básico adequado, com tratamento de esgoto empregando inclusive técnicas terciárias, capazes de gerar um efluente cada vez mais inócuo para o ambiente, permitiria que a prática do reuso indireto de água fosse usada de forma complementar ao reuso direto da água (onde o esgoto tratado pode ser utilizado para irrigação, recreação ou abastecimento público) garantindo não só a oferta, mas a qualidade das águas e, consequentemente a saúde da biota aquática e do homem, principalmente nas grandes regiões metropolitanas do país. ${ }^{39}$

\section{Matriz: água superficial}

A água superficial foi a matriz mais estudada com um total de 44 trabalhos publicados, visto a sua importância para a garantia dos usos múltiplos da água em um país onde as condições de saneamento básico não favorecem a preservação destes recursos e, como resultado, inúmeras substancias já foram quantificadas em rios de 9 dos 26 estados brasileiros onde as pesquisas foram realizadas (Figura 2). Essa tendência também pode ser explicada do ponto de vista analítico, uma vez que as águas superficiais são, na maioria das vezes, matrizes menos complexas que o esgoto, por exemplo. Outro fator é que as concentrações de contaminantes nas águas superficiais são, em geral, maiores que nas águas tratadas, conseguindo ser determinadas por equipamentos com detectores menos sofisticados. Uma discussão mais detalhada com relação às técnicas analíticas será apresentada mais adiante.

A revisão da literatura apresentou 44 artigos publicados em revistas indexadas sobre a presença de contaminantes emergentes em águas superficiais do Brasil, que totalizaram 193 compostos de diferentes classes em aproximadamente 75 corpos d'água de 9 dos 26 estados brasileiros (Tabela 1, Tabela 1S e Figura 2). Do total de compostos estudados, 62\% (98 compostos) foram quantificados em pelo menos uma amostra incluindo fármacos, ${ }^{4,24,40-46}$ produtos de higiene pessoal, ${ }^{7,24,25,40,41,46,47}$ cafeína, ${ }^{7,24,40-42,46-50}$ hormônios, ${ }^{7,9,18,20-22,40-42,46,51-54}$ drogas ilícitas, ${ }^{26,45,46}$ compostos de uso industrial ${ }^{7,9,20,22,42,44,46,51-53,55} \mathrm{e}$ pesticidas. ${ }^{2,3,7,24,29-31,46,55-68}$ As concentrações variaram cerca seis ordens de grandeza, com valores entre 0,3 e 753,500 $\mathrm{ng} \mathrm{L}^{-1}$ (Tabela 1).

O estágio de contaminação dos corpos d'água reflete o uso e ocupação do solo de cada região, logo, está diretamente relacionado com o grau de saneamento básico, bem como a densidade populacional e o tipo de economia dos diferentes estados brasileiros.

Os pesticidas foi a classe de compostos mais estudada (22 artigos publicados), visto que a temática de contaminação por estas substancias antecede as discussões sobre os contaminantes de preocupação emergente. Alguns são regulamentados no Brasil e os estudos envolvendo a exposição a esses agentes tóxicos vão muito além da contaminação das águas, estando relacionados principalmente aos alimentos e a exposição ocupacional. Do ponto de vista ambiental, os corpos d'água são as matrizes mais vulneráveis a contaminação indireta a qual pode estar em níveis de nanogramas a microgramas por litro, o que justifica o maior número de trabalhos sobre a contaminação por essa classe de compostos no país que é hoje o maior consumidor de pesticidas do mundo.

Albuquerque e colaboradores publicaram uma revisão crítica sobre a presença de pesticidas nos corpos d'água superficiais do Brasil juntamente com uma avaliação do risco para a vida aquática. No trabalho é destacado a escassez de dados para o país, uma vez que foram encontrados estudos sobre a presença de pesticidas em apenas 5 dos 27 estados brasileiros, o que corrobora com os dados apresentados neste trabalho. Os autores verificaram ainda, que a classe dos herbicidas foi a mais estudada até o momento, no entanto, os inseticidas foram os que apresentaram os maiores riscos para a biota aquática. ${ }^{69}$

Os compostos oriundos das atividades doméstica e industrial do homem foram estudados principalmente nos rios da região sul e sudeste, as quais concentram o maior número de pessoas e indústrias, o que remete aos cenários mais críticos de contaminação. Apesar dos índices e saneamento básico serem considerados mais elevados nestas regiões, a quantidade em massa de efluente bruto lançados diretamente nos corpos d'água aliada a baixa vazão dos rios, compromete todos os usos da água. Compostos como PPCP e hormônios, foram determinados em concentrações entre $0,3 \mathrm{ng} \mathrm{L}^{-1}$ a 753,5 $\mu \mathrm{g}$ $\mathrm{L}^{-1}$, enquanto que em países da Europa e nos Estados Unidos, por exemplo, as concentrações máximas reportadas são da ordem de 2,0 $\mu \mathrm{g} \mathrm{L}{ }^{-1} .{ }^{17,37}$ Outros trabalhos de revisão sobre a presença de fármacos no Brasil também destacaram a escassez de dados e a grande faixa de variação das concentrações destes contaminantes nos diferentes corpos d'água do país. ${ }^{70-72}$

Para a determinação dos compostos nos corpos d'águas superficiais, os diferentes autores empregaram tanto a cromatografia líquida (LC) quanto a gasosa (GC) e os mais diferentes detectores, o que favoreceu uma variação muito grande nos limites de detecção dos métodos analíticos e, portanto, os mesmos foram mencionados na Tabela $1 \mathrm{~S}$ e apenas os valores acima dos limites de quantificação dos métodos analíticos foram apresentados nesta revisão.

\section{Matriz: água subterrânea}

Os estudos realizados em amostras de águas subterrâneas estão concentrados no Estado do Mato Grosso, ${ }^{56-60,73}$ em São Paulo ${ }^{2,25}$ e em Santa Catarina $^{74}$ e, apenas para a determinação de pesticidas, com exceção para o trabalho de Silva e colaboradores, que avaliaram a presença de compostos usados como filtros UV em protetores solares em amostras de manaciais subterrâneos no interior do Estado de São 
Paulo. Neste trabalho, o metoxicinamato de etilhexila foi o único contaminante determinado acima dos limites de quantificação do método analítico, o qual empregou extração em fase sólida e GC-MS/ MS, em concentração de $137 \mathrm{ng} \mathrm{L}^{-1} .^{25}$

Com relação aos pesticidas, foram 30 princípios ativos determinados, além dos derivados da atrazina, que foi o herbicida mais estudado no país e, apesar de ser proibido em alguns países, está entre os mais consumidos no Brasil, de acordo com o IBAMA. ${ }^{75}$ As concentrações de atrazina variaram entre 10 e $18900 \mathrm{ng} \mathrm{L}^{-1}$. A atrazina e o aloclor foram os pesticidas mais frequentemente dectados dentre os 27 que foram monitoramento nas águas subterrâneas da Slovenia de acordo com Gotvajn e colaboradores. ${ }^{76} \mathrm{Na}$ Grécia, o monitoramento das águas subterrâneas da Macedônia Central apontaram a atrazina, alaclor, desetilatrazina (DEA), metolaclor, simazina e carbofurano entre os mais frequentemente detectados dentre as cem amostras analisadas entre 1996 e $1997 .{ }^{77}$ A determinação dos derivados de compostos, como os da atrazina (deisopropilatrazina (DIA), (DEA) e 2-hidroxiatrazina) por exemplo, é importante para se entender o destino deles no ambiente e poder inferir sobre a toxicidade mesmo após um longo período da aplicação.

Em Chapecó (SC), Olivo e colaboradores determinaram as concentrações de glifosato, que é o agrotóxico mais consumido no Brasil, em 13 diferentes poços tubulares profundos e as concentrações variaram entre 246 e $6800 \mathrm{ng} \mathrm{L}^{-1}$, com uma frequência de detecção de $38 \%$. A determinação de glifosato foi feita empregando SPE, derivatização, e HPLC-FLD com limite de quantificação de $240 \mathrm{ng} \mathrm{L}^{-1} .{ }^{74}$ A Figura 5 apresenta as concentrações máximas obtidas para os pesticidas que foram quantificados em pelo menos uma amostra de água subterrânea. A Tabela 1 mostra que as concentrações variaram entre 10 e $68790 \mathrm{ng} \mathrm{L}^{-1}$ nas diferentes amostras estudadas.

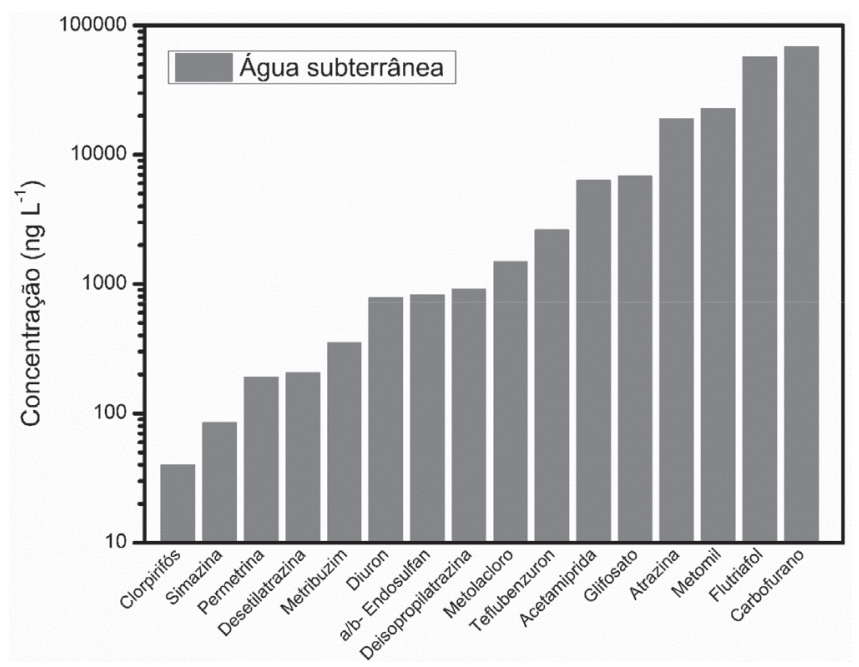

Figura 5. Concentrações dos pesticidas quantificados em pelo menos uma amostra de água subterrânea do Brasil de acordo com os dados descritos na Tabela $1 S$

Ribeiro e colaboradores descreveram sobre as dificuldades e os custos para o monitoramento de águas subterrâneas, bem como a importância em se conhecer o destino, principalmente dos pesticidas após a sua aplicação. Tal contaminação, depende da natureza química de cada substancia, bem como o tipo de solo e, consequentemente a mobilidade na interface água/solo. ${ }^{78}$ Além dos pesticidas, os fármacos veterinários seguem essa mesma rota após serem administrados e, portanto, requerem estudos semelhantes. Por outro lado, é de se esperar que a contaminação das águas subterrâneas por compostos de origem doméstica ou industrial seja mais susceptível próximos aos poços e áreas de recargas.

\section{Matriz: água envasada}

Para esta matriz, foi encontrado um trabalho que investigou a ocorrência de 16 compostos perfluorados (PFCs) em nove amostras adquiridas no ano de 2014 e 8 analitos foram detectados. As maiores frequências de detecção foram encontradas para os compostos: ácido perfluoroheptanóico (PFHpA, 67\% de amostras positivas), ácido perfluorobutanossulfônico (PFBS, 50\%), ácido perfluorooctanóico (PFOA, 33\%) e ácido perfluorohexadecanoico (PFHxDA, 33\%). Os compostos detectados ocorreram em concentrações de 2,6 a 15 $\mathrm{ng} \mathrm{L^{-1 }}$. O ácido perfluorooctanossulfônico (PFOS) não foi detectado em nenhuma amostra. ${ }^{28}$ Os PFCs são muito estáveis devido ao caráter da ligação C-F e são considerados poluentes orgânicos persistentes (POP).

A preocupação com a presença dos contaminantes emergentes nas águas de abastecimento público remetem à preocupação com a saúde humana. É sabido que a qualidade da água que é servida à população reflete tanto a qualidade do manancial como a eficiência do tratamento, e que a presença destes compostos e os riscos associados a eles, não estão contemplados nas regulamentações vigentes pelos diferentes motivos que estão sendo discutidos neste trabalho. Diante deste cenário, é comum as pessoas inferirem que o consumo de água envasada (ou água mineral) traga menor risco à saúde e, portanto, esse tópico também foi brevemente discutido, de forma a complementar a temática relacionada a esse uso da água.

As águas naturais, principalmente as águas minerais, podem ser envasadas e a partir de então são comercializadas como um alimento. Neste processo, o interessado deve obter a Concessão de Lavra da água de acordo com o Código de Mineração; com a Resolução CONAMA n. ${ }^{\circ}$ 09, de 06/12/90, referente ao Licenciamento Ambiental e com a Portaria n. ${ }^{\circ}$ 374/09 do DNPM (Departamento Nacional de Produção Mineral), através da Norma Técnica n. ${ }^{\circ}$ 01/09, a qual descreve as Especificações Técnicas para o Aproveitamento das Águas Minerais e Potáveis de Mesa. ${ }^{79}$

O Brasil, em 2013, estava classificado em décimo nono lugar no ranking dos países com maior consumo per capita de água mineral envasada. Por esta estatística, atribuiu-se a cada brasileiro o consumo anual de 90,3 L ${ }^{80}$ Questiona-se, no entanto, se o vasto mercado de água envasada é a imagem da pureza esperada do produto e se há regulamentações que assegurem a qualidade da bebida, preservando a saúde humana. A legislação brasileira possui uma Resolução da Agência Nacional de Vigilância Sanitária (ANVISA) que versa sobre água envasada ( $\operatorname{RDC~}^{\circ} 274$, de 22 de setembro de 2005). Nesta Resolução, são definidos limites máximos de concentração de alguns compostos orgânicos que podem estar presentes neste produto.

Em 2007, foi realizado um estudo de ocorrência de ftalatos em amostras de água mineral envasada adquiridas no comércio local da cidade de Campinas/SP. Foram alvo de estudo os ftalatos de dimetila (DMP), dietila (DEP), butil-benzila (BBP), di-n-butila (DnBP), di-(2-etil-hexil) (DEHP) e di-n-octila (DnOP). Para 6 amostras de água sem gás, a frequência de detecção de DMP, DEP e DnOP foi de 17\%, para o DEHP foi de $33 \%$, para o BBP foi de $67 \%$ e o ftalato que foi mais frequentemente encontrado foi o DnBP, ocorrendo em $83 \%$ das amostras. Das 4 amostras gaseificadas, não foram detectados os compostos DMP, DEP, DnOP, a frequência de detecção do BBP foi de $50 \%$ e tanto o DnBP quanto o DEHP ocorreram em $75 \%$ delas. Em seguida, a segunda etapa desse estudo consistiu em análises ao longo da vida de prateleira da água envasada. No estudo temporal, o ftalatos detectados foram o DnBP, DEHP, DEP e o BBP, com um mínimo de $1 \mu \mathrm{g} \mathrm{L}^{-1}$ para DEP e BBP, um máximo de $4 \mu \mathrm{g} \mathrm{L}^{-1}$ para o DnBP e os valores foram similares ao longo do tempo. A baixa variação de resultados entre os meses de estocagem, embalagem (PP, PET e vidro) e tipo de água (com e sem gás) sugeriram que a origem mais provável 
de contaminação seja do processo de envase ou até mesmo da fonte natural da água, no entanto, o que é ainda mais preocupante, foi a persistência dos compostos durante a vida de prateleira do produto mostrando que não houve degradação destes compostos. ${ }^{81}$

Com relação à qualidade da água envasada, a RDC nº 274/05 da Anvisa não apresenta nenhum parâmetro relacionado a presença de ftalatos e compostos perfluorados. Mesmo que a Portaria 2914/11 do Ministério da Saúde contemple um valor máximo de DEHP para a água potável $\left(8 \mu \mathrm{g} \mathrm{L}^{-1}\right)$, essa Portaria não tem alcance para as águas envasadas, cuja responsabilidade de fiscalização é da Anvisa, tampouco para fontes subterrâneas, cuja responsabilidade é do CONAMA.

\section{Fontes e destino no ambiente}

As propriedades físico-químicas dos contaminantes ditam seus destinos no ambiente e também são usadas para se obter o melhor método analítico para a determinação em amostras ambientais. A solubilidade em água $\left(\gamma_{\text {sat }}\right)$ estabelece a concentração máxima do contaminante dissolvido e é dependente do $\mathrm{pH}$, da temperatura e da presença de materiais particulados ou matéria orgânica nas amostras ambientais. Os coeficientes de partição e de adsorção e a hidrofobicidade influenciam na distribuição dos contaminantes entre os diferentes compartimentos: água, sedimento e biota aquática. A biomagnificação é resultante de uma série de etapas de bioacumulação que podem ocorrer na cadeia alimentar, a qual é agravada devido à exposição crônica aos contaminantes. A volatilidade de uma substancia nos corpos d'água é determinada pela Constante de Henry, porém, dentre os contaminantes emergentes aquáticos abordados neste trabalho, poucos compostos apresentam volatilidade suficiente para que a transferência da fase aquosa para a atmosférica seja um sumidouro efetivo. ${ }^{82}$

Para fármacos, hormônios, drogas de abuso e compostos presentes em produtos de higiene pessoal e doméstico, pode-se prever como principal fonte de contaminação os efluentes das ETE. No entanto, o Censo 2010 do Instituto Brasileiro de Geografia e Estatística (IBGE) indicou que apenas $32,9 \%$ da população brasileira possui rede coletora de esgoto e apenas parte deste esgoto coletado recebe algum tipo de tratamento antes de ser lançado aos corpos d'água. ${ }^{83}$ Ou seja, é de se esperar que a qualidade dos mesmos reflita o cenário de uso e ocupação da bacia na qual está inserido, uma vez que, muito embora as grandes cidades apresentem elevados índices de coleta $\mathrm{e}$ tratamento de esgoto, ainda há grande aporte de esgoto in natura sendo lançado diretamente nos recursos hídricos comprometendo assim a qualidade das águas.

Para os compostos de uso industrial, os próprios efluentes industriais gerados durante o processo são as principais fontes de contaminação para o ambiente. A regulamentação que rege os padrões de emissão de poluentes (CONAMA 430/2011) especifica valores máximos permitidos para alguns metais, óleos e solventes orgânicos, assim como parâmetros físico-químicos, mas não especifica outras substancias. Como consequência, ela "permite" que outros contaminantes sejam lançados para os corpos d'água. Nestes casos, a principal fonte de atenuação acaba sendo a diluição, o que não necessariamente minimiza os efeitos potenciais de muitos contaminantes. Mesmo com a diluição, estes compostos ainda podem ser detectados em rios pertencentes a áreas com intensa atividade industrial em concentrações capazes de causar efeitos adversos em organismos saudáveis. . $, 9,20,22,42,44,46,51-53,55$ Além do efluente, o produto manufaturado é outra fonte difusa destes contaminantes. Eles são liberados do produto por meio de lixiviação, entretanto, esta via contribui minoritariamente para o estoque destas substancias nas matrizes ambientais.

O cenário de contaminação por compostos oriundos de efluentes industriais, hospitalares e domésticos é agravado nos períodos de estiagem, uma vez que não há o efeito de diluição causado pelas chuvas. Por outro lado, ao analisar o cenário de contaminação por compostos oriundos das atividades agrícola e pecuária, é possível inferir que as concentrações destes nos corpos d'água sejam maiores em períodos de chuvas devido a lixiviação dos solos. Além disso, a aplicação via aérea de pesticidas pode ser considerada outra grande fonte de contaminação dos corpos aquáticos.

Majewsky e colaboradores estudaram o balanço de massa de cinco contaminantes emergentes: sucralose e acesulfame (adoçantes artificiais), iopromida e omnipaque (agentes de contraste) e a carbamazepina (fármaco utilizado no tratamento de epilepsias) no Lago Paranoá localizado em Brasília (DF), um importante reservatório usado como fonte de água para abastecimento público e que recebe efluentes de ETE em diferentes pontos. Os autores indicaram um aumento lento na concentração dos compostos persistentes e uma situação de estado estacionário para os compostos mais facilmente degradáveis, além disso, o cenário analisado mostrou uma projeção onde a redução das emissões devido aos investimentos em tratamentos terciários nas ETE só seria observada depois de dez anos, devido ao elevado tempo de residência neste reservatório. ${ }^{84}$

\section{Sobre as diferentes classes de contaminantes emergentes determinadas no Brasil}

Diferentes classes de compostos foram determinadas nas diferentes matrizes aquáticas brasileiras, conforme discutido anteriormente e, a seguir, está apresentado uma breve discussão sobre cada uma dessas classes.

Os fármacos pertencem a uma das classes de contaminantes emergentes mais estudadas em todo o mundo (sendo a segunda mais estudada no Brasil), pois são constantemente lançados no ambiente em grandes quantidades, além de serem produzidos com a finalidade de apresentarem efeitos biológicos. Muitos são persistentes e lipofílicos, podendo ser bioacumulados, outros são parcialmente metabolizados pelo organismo e seus metabólitos, lançados no ambiente, também podem causar efeitos à biota e ao homem.

Os fármacos incluem todas as drogas consumidas com ou sem prescrição médica, de uso humano ou veterinário, e suplementos alimentares. Nas últimas décadas houve um aumento significativo no consumo de medicamentos em todo o mundo, inclusive no Brasil, ${ }^{72}$ principalmente aqueles vendidos sem prescrição médica, como os analgésicos e antitérmicos e aqueles de uso contínuo como os reguladores lipídicos, anticoncepcionais e antidepressivos. O mercado farmacêutico mundial movimenta bilhões de dólares anualmente, com um crescimento de mercado que tem se expandido tanto em quantidade como em variedade de novos princípios ativos ${ }^{85}$ (existem aproximadamente 3000 compostos diferentes sendo usados como ingredientes ativos de fármacos em todo o mundo). ${ }^{1}$

A presença de fármacos em amostras ambientais tem sido reportada desde a década de 70 em concentrações de nanogramas a microgramas por litro. ${ }^{86,87}$ Os dados apresentados na Tabela 1 podem ser complementados com a revisão de Quadra e colaboradores os quais selecionaram além dos artigos descritos neste trabalho, algumas dissertações e teses defendidas em diferentes Universidades do Brasil para discorrer sobre os efeitos da presença de fármacos nos sistemas aquáticos brasileiros. ${ }^{72}$

As maiores preocupações são com os fármacos de origem hormonal, dado seu potencial de interferência endócrina; os fármacos psicoterápicos, que agem diretamente no sistema nervoso central; e os antimicrobianos devido ao fato de promoverem um aumento na quantidade de bactérias resistentes. Este último, vem recebendo grande destaque na Organização Mundial da Saúde (OMS ou WHO, do inglês World Health Organization) nos últimos anos e, em 2016 
foi lançado um alerta mundial sobre esta problemática, a qual países do mundo todo deverão participar com ações de grande, médio e pequeno porte com objetivo de minimizar os efeitos da resistência aos antimicrobianos. De acordo com a OMS, são necessários inovações e investimentos em pesquisa e desenvolvimento de novos medicamentos antimicrobianos, vacinas e instrumentos de diagnóstico. ${ }^{88}$

Presente em alguns medicamentos do tipo analgésico, antigripais e inibidores de apetite, a cafeína, estudada em 12 dos 58 trabalhos incluídos nesta revisão ( 20\%), é um dos produtos mais consumidos no mundo, podendo ser encontrada também em cerca de 60 espécies de plantas, em diversos produtos alimentícios como café, chás, cola, chocolate, guaraná, condimentos, além do tabaco. A cafeína pertence ao grupo de compostos químicos chamados xantinas que são substâncias capazes de estimular o sistema nervoso, produzindo um estado de alerta de curta duração. ${ }^{89} \mathrm{~A}$ absorção da cafeína no organismo é muito rápida, assim como a distribuição, passando rapidamente para o sistema nervoso central. O corpo humano não necessita de cafeína e o seu consumo moderado não está associado a nenhum risco à saúde, exceto em algumas situações especiais, como a gestação e a hipertensão, por exemplo.

A presença de cafeína nos corpos d'água é sobretudo de origem antrópica. Estudos têm mostrado que a cafeína é altamente metabolizada pelo organismo e, apesar de apenas $3 \%$ da quantidade ingerida ser excretada pela urina na forma in natura, ${ }^{89}$ a quantidade que chega ao ambiente (via excreção ou outras rotas) é suficiente para ser detectada por meio de técnicas analíticas simples, como por exemplo, a cromatografia líquida acoplada ao detector de absorção no ultravioleta (UV). ${ }^{42,48-50,90}$

A cafeína ocorre em altas concentrações (até $\mathrm{mg} \mathrm{L}^{-1}$ ) no esgoto e, por ser um composto estável e bastante solúvel em água, ela é parcialmente removida pelas ETE, podendo remanescer em corpos d'água superficiais e, consequentemente, em águas destinadas ao abastecimento público provenientes de mananciais impactados. ${ }^{6,23}$ Por esses motivos, a cafeína tem sido considerada um marcador químico sensível e específico de atividade antrópica e vem substituindo outros marcadores biológicos de esgoto como, por exemplo, o $E$. Coli. ${ }^{6,48,49,89-92}$ Um outro estudo correlacionou ainda a concentração de cafeína com o potencial estrogênico de amostras de águas superficiais, pois mesmo não sendo considerada um interferente endócrino, é oriunda do esgoto doméstico, o qual apresenta uma série de outros compostos que podem causar alterações no sistema endócrino. ${ }^{93}$

De acordo com os trabalhos considerados nesta revisão, não houve publicação em revista indexada focado na ocorrência de cafeína em esgoto, enquanto que houve 10 trabalhos que determinaram este composto em amostras de águas superficiais, em concentrações entre 0,29 e $753500 \mathrm{ng} \mathrm{L}^{-1}$, e 4 trabalhos a quantificaram em amostras de água tratada em concentrações entre 1,8 e $5800 \mathrm{ng} \mathrm{L}^{-1}$. Estas concentrações estão na mesma ordem de grandeza que aquelas determinadas em efluentes tratados de outros país de acordo com Sodré e colaboradores. ${ }^{23}$

Os produtos de higiene pessoal referem-se aos cosméticos, fragrâncias, compostos antimicrobianos, antioxidantes e cremes preservativos, inseticidas repelentes e os protetores solares, cujo consumo mundial vem aumentando exponencialmente na última década. Muitos compostos usados nestes produtos são lipossolúveis e, portanto, possuem alto potencial de bioacumulação, ${ }^{1}$ e além disso, alguns são parcialmente removidos pelos processos de tratamento convencionais de água e esgoto. ${ }^{17}$ Desde 2010, o Brasil ocupa a $3^{\circ}$ posição no consumo mundial, perdendo apenas para os EUA e Japão, de acordo com a Associação Brasileira da Indústria de Higiene Pessoal, Perfumaria e Cosméticos (Abihpec), o que pode nos remeter a um cenário típico de contaminação ambiental, principalmente nas regiões sul e sudeste do país onde a densidade populacional é mais alta.
Com relação às drogas ilícitas ou drogas de abuso, a preocupação ambiental foge do aspecto regulatório uma vez que são ilícitas. Os trabalhos descritos na literatura abordam métodos analíticos para a determinação em concentrações traços, ${ }^{94-97}$ apresentam dados de ocorrência em esgoto, ${ }^{15,95-98}$ em corpos d'água superficiais ${ }^{26,45,46,94,95,98,99}$ e na água tratada, ${ }^{26,100}$ e buscam por endpoints ecotoxicológicos que possibilitem correlacionar um efeito a uma concentração, permitindo que uma avaliação do risco tanto para a biota aquática quanto para a saúde humana possa ser analisada com clareza. O Escritório das Nações Unidas sobre Drogas e Crimes (UNODC - do inglês, United Nations Office on Drugs and Crime), órgão internacional que implementa medidas para o combate e controle do uso de drogas, considera o termo droga ilícita não apenas a identidade química da substância, mas todo o seu ciclo desde a intenção da produção até o seu consumo. A cannabis, as anfetaminas, a cocaína e os opiáceos estão entre as classes mais consumidas, correspondendo a aproximadamente $90 \%$ do consumo mundial. Entretanto, a prevalência e os padrões de uso variam entre países. No Brasil, os últimos dados publicados pelo Observatório Brasileiro de Informações sobre Drogas (OBID) e pelo UNODC relataram a cannabis e a cocaína como as classes de maior consumo entre os usuários. ${ }^{101}$

Alguns compostos de uso industrial também são classificados como contaminantes emergentes, tendo sido determinado em amostras de esgoto, águas superficiais e de abastecimento público no Brasil em concentrações entre 0,04 e $78250 \mathrm{ng} \mathrm{L}^{-1}$. Dentre eles, pode-se citar o bisfenol A, os alquilfenóis, as bifenilas policloradas, os ftalatos, os compostos perfluorados (PFC, do inglês perfluorinated compounds) $\mathrm{e}$ os retardantes de chama bromados. ${ }^{117}$ A maior preocupação está nas quantidades em que são lançados ao ambiente, uma vez que a maioria destes compostos não possui padrões de emissão e, portanto, não há um valor máximo designado especificamente ao lançamento deste tipo de contaminante pelo efluente. Alguns países têm adotados valores de referência para a gestão de algumas substâncias consideradas mais relevantes do ponto de vista de contaminação ambiental, como exemplos, a Directive 2008/105/EC da European Parliament and The Council e a Canadian Environmental Protection Act. ${ }^{17}$ Muitos são lipossolúveis e alguns deles são ainda classificados como poluentes orgânicos persistentes.

O bisfenol A é um dos compostos mais estudados em matrizes ambientais. É utilizado no processo de obtenção de resinas do tipo epóxi e alguns polímeros, podendo ser aplicado em embalagens de alimentos, produtos infantis, entre outros. ${ }^{102}$ Alquilfenóis são utilizados nas indústrias de óleos lubrificantes, resinas, plásticos e borrachas, como aditivos ou plastificantes. Especialmente o nonilfenol pode ser disponibilizado no ambiente por ser produto de degradação de seu análogo etoxilado, utilizado em detergentes. ${ }^{8,42,53}$ As bifenilas policloradas são usadas em fluidos hidráulicos e de transferência de calor, lubrificantes, em capacitores dielétricos e como plastificantes, mesmo tendo sua produção banida na década de $80,{ }^{82}$ devido as características físico químicas de persistência, resíduos dessas substâncias ainda são possíveis de serem detectados nos corpos d'água. ${ }^{55}$ Os ftalatos são amplamente utilizados como plastificantes e são alvo de pesquisas que buscam conhecer a sua ocorrência em diversas matrizes além da ambiental, como bolsas de soro, de sangue, em brinquedos, alimentos, cosméticos e plásticos. ${ }^{103}$ Os compostos perfluorados são aplicados em modificações de superfícies, como por exemplo, obtenção de superfícies antiaderentes, são utilizados como surfactantes, assim como em espumas de combate a incêndio e também em embalagem de alimentos. Por ocorrerem por longos períodos no ambiente sem sofrerem degradação, os PFC são considerados poluentes orgânicos persistentes. Os retardantes de chama bromados têm sido usados em diferentes produtos tais como tecidos, eletrônicos, plásticos e espumas poliuretanas, no entanto, são compostos orgânicos persistentes 
no ambiente e que têm sido determinados em locais distantes das fontes de emissão. ${ }^{1}$

Uma outra classe de contaminantes preocupantes sob o ponto de vista ambiental é a dos pesticidas. De acordo com os dados desta revisão, é a classe de compostos mais estudada no país considerando o número de trabalhos e a quantidade de ingredientes ativos investigados. Foram reportados 22 trabalhos em amostras de águas superficiais, 8 em amostras de águas subterrâneas, 7 em amostras de água de abastecimento público e mais de 120 pesticidas diferentes.

O cultivo agrícola gera um desequilíbrio biológico na natureza seja pela remoção de culturas competitivas, pelo uso de linhagens obtidas por seleção, falta de revezamento de culturas numa única área de plantio, adubação, irrigação, poda ou controle de pragas. $\mathrm{O}$ aumento da população mundial e, consequentemente, o aumento pela demanda de alimentos, aliado as práticas modernas de cultivo, consolidaram os pesticidas como a principal ferramenta para assegurar a proteção contra perdas na produção ou destruição de culturas. Há, portanto, uma disseminação de diferentes substâncias químicas desenvolvidas para atuar em um conjunto específico de pragas, mas que acabam sendo potencialmente danosas a organismos não alvos incluindo a biota e o homem. ${ }^{104}$

A preservação da qualidade ambiental é um dos principais desafios deste cenário, tendo em vista a grande quantidade de pesticidas que são lançados no ambiente. O Brasil é o maior consumidor de pesticidas do mundo. De acordo com o último Boletim de Comercialização de Agrotóxicos e Afins publicado pelo Ministério do Meio Ambiente (MMA) através do Instituto Brasileiro do Meio Ambiente e dos Recursos Naturais Renováveis (IBAMA) foram comercializadas aproximadamente 478 mil toneladas de ingredientes ativos no país entre 2009 e 2012, o que representou um aumento médio de cerca de $234 \%$ quando comparado à 2006. Esse documento mostrou ainda que a classe dos herbicidas foi a mais comercializada, com a venda de 299 mil toneladas em 2012, seguida pelos fungicidas (60 mil toneladas) e acaricidas (37 mil toneladas). ${ }^{75}$

Ainda assim, a regulação brasileira é deficitária em seus critérios de qualidade de água. Estes são baseados em agências regulamentadoras de outros países ou na OMS e não consideram a variedade de pesticidas utilizados nas diferentes regiões do Brasil, as características particulares da agricultura nacional, além dos efeitos potenciais causados devido à exposição crônica mesmo em concentrações extremamente baixas, da ordem de picograma a nanograma por litro, como as encontradas nas amostras ambientais.

\section{COMPOSTOS INTERFERENTES ENDÓCRINOS}

Dentre os contaminantes emergentes, alguns compostos são ainda classificados pelos seus potenciais ou capacidades de alterarem as funções do sistema endócrino e, consequentemente, causar efeitos adversos em um organismo saudável ou em seus descendentes. ${ }^{105}$ São denominados interferentes endócrinos e definidos pela USEPA como "um agente exógeno que interfere na síntese, secreção, transporte, ligação, ação ou eliminação dos hormônios naturais no corpo que são responsáveis pela manutenção da homeostase, reprodução, desenvolvimento elou comportamento". ${ }^{106}$

Os interferentes endócrinos podem pertencer a diferentes classes. São exemplos os hormônios naturais e sintéticos, os fitoestrogênios, os alquilfenóis, os retardantes de chama bromados, o bisfenol A, ftalatos, os hidrocarbonetos policíclicos aromáticos (HPA), as bifenilas policloradas, e alguns pesticidas. ${ }^{1,107-109}$

Agências ambientais e organizações não-governamentais classificam os interferentes endócrinos em três classes principais: os estrogênios naturais, os estrogênios sintéticos e os xenoestrogênios. Os estrogênios sintéticos apresentam maior capacidade de interferir no sistema endócrino humano em comparação aos demais tipos de estrógenos, enquanto que os xenoestrogênios são menos potentes, porém mais prováveis de serem encontrados no ambiente.

Os estrogênios naturais fazem parte de um grupo de vários hormônios lipossolúveis produzidos principalmente nos ovários, mas também em quantidades consideráveis na placenta e em menores quantidades nos testículos e no córtex adrenal. Os hormônios estradiol, estrona e estriol são os três principais estrogênios endógenos. Além destes, a progesterona e a testosterona são exemplos de outros hormônios naturais que, assim como os estrogênios, são excretados diariamente pela urina e podem ser determinados nos corpos d'água que recebem grandes aportes de esgoto doméstico. . $^{7,9,18,20-23,40-42,46,51-54}$

Os estrogênios sintéticos, encontrados em produtos farmacêuticos, são esteróides que tiveram suas estruturas moleculares alteradas. Os principais usos estão relacionados aos contraceptivos, terapias de reposição hormonal e tratamento de neoplasias. São compostos sintetizados para agirem diretamente no sistema endócrino, por isso possuem alto potencial estrogênico.

O termo xenoestrogênio é aplicado a uma série de substâncias químicas produzidas pelo homem que confundem os receptores celulares dos estrogênios no organismo, interferindo nas mensagens bioquímicas naturais. Podem ou não ser compostos do tipo esteroidais, tendo a habilidade de mimetizar ou bloquear a atividade dos hormônios endógenos, bem como alterar a forma como os hormônios e seus receptores proteicos atuam, são produzidos e/ou metabolizados. ${ }^{82} \mathrm{O}$ mecanismo de ação depende da estrutura química de cada molécula, assim como o potencial estrogênico e, consequentemente, os efeitos observados nos organismos.

\section{Efeitos relacionados à presença de compostos interferentes endócrinos no ambiente}

A preocupação com a presença de xenoestrogênios no ambiente teve seus primeiros relatos no final dos anos 30 quando Dodds e Lawson reportaram sobre a atividade estrogênica do bisfenol A, ou seja, a capacidade de agir no sistema endócrino de animais e seres humanos, e a partir de então, outros pesquisadores começaram a discutir a possibilidade de alguns compostos terem a habilidade de minimizar a ação dos hormônios endógenos. ${ }^{110-112}$

O livro "Primavera Silenciosa", de autoria de Rachel Carson, publicado em 1962, ${ }^{113}$ mostrou de inúmeras formas os efeitos nocivos à saúde humana e aos animais provocados pela exposição ao DDT (dicloro-difenil-tricloroetano). DDT foi determinado em amostras superficiais do Brasil em concentrações entre 6 e $130 \mathrm{ng} \mathrm{L}^{-1},{ }^{30,55} \mathrm{e}$ alguns estudos apontam para a possibilidade de afetar as gerações futuras devido ao potencial de bioacumulação deste pesticida. ${ }^{105} \mathrm{~A}$ Revolução Verde iniciou-se nos anos 60, impulsionou a produção agrícola e, com isso, houve uma grande disseminação do uso de pesticidas que foram desenvolvidos e comercializados com poucas restrições de regulamentação.

Em 1965, Stumm-Zollinger e Fair publicaram o primeiro artigo indicando que os estrógenos não são completamente eliminados pelas ETE. ${ }^{114}$ Em 1970, Tabak e Bunch investigaram o destino dos esteróides durante o tratamento de esgoto e afirmaram sobre a importância de se estudar a degradação deles nas ETE e no ambiente, uma vez que estes compostos são fisiologicamente ativos mesmo em baixas concentrações. ${ }^{115}$ Isso corrobora com a preocupação com relação à presença e às concentrações destas substâncias nos diversos efluentes analisados no Brasil, em que $60 \%$ dos trabalhos determinaram esta classe de compostos (Figura 1).

Apesar dos primeiros relatos relacionados a presença dos interferentes endócrinos no ambiente datarem da década de 1960, o assunto não ganhou importância significativa até os anos 90, quando 
a presença de hormônios naturais e sintéticos em ETE foram relacionadas com o impacto na reprodução de peixes expostos aos efluentes da ETE. ${ }^{16,117}$ A partir de então, iniciaram-se os estudos com foco na ocorrência destes contaminantes em ETE e nos corpos d'água em níveis de sub microgramas por litro. ${ }^{4,118-120}$ Paralelamente, estudos in vitro e in vivo começaram a ser reportados sobre os possíveis mecanismos de ação de compostos xenoestrogênios no organismo de mamíferos. ${ }^{121-125}$

Um dos exemplos mais conhecidos é o caso envolvendo a contaminação de crocodilos no lago Apopka (Flórida/EUA), na década de 1980. Na ocasião, alguns pesquisadores notaram que a população desses animais estava diminuindo ano a ano. Estudos subsequentes demonstraram que a exposição contínua de alguns pesticidas, mesmo em concentrações baixas, sobre os ovos da espécie interferiu no desenvolvimento do sistema reprodutor dos animais, tornando-os inférteis. ${ }^{126}$

Uma evidência dos possíveis efeitos provocados pela exposição humana aos interferentes endócrinos foi observada entre os anos 50 e 70 com mulheres grávidas que tomaram dietilestilbestrol, um estrogênio sintético prescrito para evitar aborto espontâneo e promover o crescimento do feto. A maioria das filhas dessas mulheres nasceu estéril e algumas desenvolveram um tipo raro de câncer vaginal. Nos filhos, provocou anormalidade nos órgãos sexuais, baixa contagem de espermatozóides e tendência a desenvolverem câncer nos testículos. ${ }^{127}$ Nos trabalhos considerados nesta revisão, o dietilestilbestrol foi analisado em águas superficiais e de abastecimento, mas não foi detectado em nenhuma amostra em concentrações acima dos limites de detecção dos métodos empregados. ${ }^{7,19}$

Apesar disso, os efeitos sobre a saúde humana associados aos interferentes endócrinos ainda não são definitivamente comprovados. Porém, outras evidências sugerem que a antecipação na idade da menarca, ${ }^{128,129}$ a diminuição da qualidade do sêmen, ${ }^{121,130-132} \mathrm{O}$ aumento da incidência de câncer de mama, ${ }^{133,134}$ obesidade ${ }^{134-136}$ e o desenvolvimento precoce do cérebro ${ }^{137}$ podem estar associadas à exposição de seres humanos em desenvolvimento frente a esses compostos. Outro trabalho discute ainda o mecanismo de transporte de compostos interferentes endócrinos, como o bisfenol A, pela placenta e aponta efeitos negativos no desenvolvimento neurológico dos bebês. ${ }^{138}$

Mnif e colaboradores apresentaram uma revisão sobre os efeitos e interferência endócrina provocados pela exposição a inúmeros pesticidas. Por exemplo, para a atrazina, um dos herbicidas mais consumidos no Brasil, foram listados efeitos como inibição androgênica, disfunções no hipotálamo e produção de prolactina, indução da produção de estrógenos, danos nas glândulas adrenais e redução do metabolismo de hormônios esteróides. ${ }^{108}$

Com relação aos ftalatos, Singh e Li reportaram vinte doenças associadas à exposição a três principais compostos (DnOP, BBP e DEHP), incluindo disfunções no sistema endócrino, genital e urológico, complicações no fígado e doenças cardiovasculares. ${ }^{139}$

Outros estudos mostraram que a exposição de diferentes organismos frente aos interferentes endócrinos levaram à ocorrência de efeitos como a feminização de peixes, ${ }^{140-149}$ alterações no desenvolvimento de moluscos e anfíbios, ${ }^{150-154}$ disfunções no metabolismo da testosterona em Daphnias ${ }^{155,156}$ e o desenvolvimento anormal de órgãos em diferentes organismos aquáticos. ${ }^{19,146,149,150,157,158}$

$\mathrm{Na}$ Índia, após observarem o declínio de cerca de $95 \%$ da quantidade de uma espécie de urubus (Oriental white-backed vulture) na década de 90, Oaks e colaboradores apresentaram fortes evidencias de que as doenças renais que afetaram os animais foram decorrentes da ingestão de resíduos de diclofenaco presentes nas carcaças de búfalos e cabras tratados com o fármaco. ${ }^{159}$ No Brasil o diclofenaco foi determinado em amostras de águas superficiais e de esgotos bruto e tratado em concentrações entre 9 e $1600 \mathrm{ng} \mathrm{L}^{-1}$. 4,12,13,24,40-42,44-46
Os efeitos causados pela presença de interferentes endócrinos em águas usadas para dessedentação de animais também foi relatado por Gotardo e colaboradores, ao correlacionar a presença de bisfenol A na água servida as cabras com a diminuição na quantidade de espermas dos animais. ${ }^{160}$

De maneira geral, muitos dos compostos determinados no Brasil já tiveram seus efeitos investigados em algum ensaio biológico, seja in vitro ou in vivo, os quais podem ser usados para discutir o cenário analisado com vistas para uma avaliação preliminar do risco associado a presença destes contaminantes nas diferentes matrizes.

\section{O ASPECTO REGULATÓRIO}

O Programa das Nações Unidas para o Meio Ambiente (UNEP, do inglês United Nations Environment Programme) e a Organização Mundial da Saúde classificam como sendo essencial e urgente o conhecimento das fontes, transformações e destino dos contaminantes emergentes no ambiente, e isso gera um grande desafio para os legisladores que precisam lidar com mais de mil substâncias diferentes que necessitam ser priorizadas para então serem regulamentadas. Esta decisão se dá frente às evidências de inúmeros danos observados às populações silvestres, bem como de possíveis alterações observadas em seres humanos e a ocorrência no meio.

Para tal, diversos países implementaram metodologias para a priorização de contaminantes ambientais. Estes métodos têm critérios definidos para avaliar, selecionar e agrupar substâncias. O resultado da aplicação da priorização geralmente gera grupos de substâncias para as quais se devem ou dar prioridade para regulamentações legais, ou priorizar pesquisas para comprovação de seus efeitos adversos, e outro grupo para as quais não é necessário tomar providências legais.

A USEPA disponibilizou em 2015 a Contaminant Candidate List-4 (CCL-4), a quarta atualização de uma lista de contaminantes candidatos a futura regulamentação nos termos da lei para águas tratadas (Safe Drinking Water Act, SDWA). Nela estão incluídos, dentre os cem compostos ou grupos químicos, estrogênios, fármacos, produtos de higiene pessoal, produtos de uso industrial e pesticidas. ${ }^{161}$

Outro programa da USEPA denominado Endocrine Disruptor Screening Program (EDSP), visa fazer uma classificação de compostos com relação à perturbação endócrina. Este programa é divido em níveis (conhecidas como Tier 1 Screening e Tier 2 Testing). A primeira estratégia (Tier 1 Screening) é baseada em estudar substâncias para identificar quais delas tem potencial para interagir com o sistema endócrino, e os compostos-alvo do estudo são selecionados com base em rotas de exposição (ex: via água tratada, via alimentos, etc.). Os compostos que são testados nesta fase Tier 1 Screening e que apresentam resposta de interferência endócrina podem ser encaminhados para os testes de efeito no sistema endócrino (Tier 2 Testing), buscando estabelecer quantitativamente a dose-resposta do efeito. Os resultados da segunda fase são utilizados para a avaliação de risco do composto. Os primeiros compostos testados foram majoritariamente ingredientes ativos de pesticidas, contidos na First List of Chemicals for Tier 1 Screening. ${ }^{162}$ Como resultado, em 2015, a USEPA destacou o potencial estrogênico em 18 das 52 substâncias testadas, descritos no documento "Tier 1 Screening Results for 52 Chemicals". ${ }^{163}$ Além disso, em 2010 foi criada a "Second List of Chemicals for Tier 1 Screening”, a qual foi revisada em 2014 e estão incluídas 109 substâncias, das quais 41 são ingredientes ativos de pesticidas e 68 são compostos identificados no âmbito da lei americana para água tratada (SDWA), sendo que a etapa Tier 2 Testing ainda não havia sido concluída até o fechamento desta revisão. ${ }^{164}$ É importante notar que a busca pelo conhecimento nos diferentes modos de ação dos compostos interferentes endócrinos é processo dinâmico e interdisciplinar 
que considera aspectos químicos, ecotoxicológicos, regulatórios e socioeconômicos da presença deles no ambiente.

Na União Europeia, as ações para levantar os compostos prioritários para serem legislados foram iniciadas em 1999. Foi definida uma metodologia para priorização de substâncias que agem ou são suspeitas de agirem como interferentes endócrinos, ${ }^{165}$ sendo que os principais critérios para a classificação das substancias em diferentes grupos foram o volume de produção, a revisão de listas de prioritários já existentes, o grau de persistência no ambiente, evidências científicas sobre os efeitos adversos e o grau de exposição da biota e de seres humanos aos contaminantes. ${ }^{166-168}$ Essa primeira lista de candidatos à priorização foi publicada no ano 2000 no relatório "Towards the establishment of a priority list of substances for further evaluation of their role in endocrine disruption" e continha mais de 500 substâncias. Depois de mais de uma década de pesquisa, os resultados científicos de relevância regulatória para a União Européia foram apresentados no documento "State of the art assessment of endocrine disruptors". ${ }^{169}$ Com relação aos contaminantes emergentes (e não necessariamente os suspeitos de serem interferentes endócrinos), Von der Ohe e colaboradores apresentaram uma nova abordagem para a avaliação do risco ecotoxicológico que foi usada para priorizar 500 contaminantes orgânicos no âmbito da European Water Framework Directive. A priorização foi feita comparando os valores conhecidos como PNEC (do inglês, Predicted No-Effect Concentration) que indica a máxima concentração que um contaminante pode estar na água e que não se espera que ocorram efeitos crônicos na biota, com os respectivos MEC (do inglês, Measured Exposure Concentration) que são as concentrações máximas do contaminante medidas na água. Os compostos que apresentam valores de MEC maior que seus respectivos PNEC são priorizados com base na frequência de detecção. ${ }^{170}$

Em 2016, de uma colaboração entre Auckland Council e Universidades da Nova Zelândia, foi publicado o relatório técnico "An Update on Emerging Organic Contaminants of Concern for New Zealand with Guidance on Monitoring Approaches for Councils" no qual foi recomendado que uma estratégia de monitoramento seja empregada no país de forma a identificar, inicialmente, classes de compostos prioritários, com base na identificação dos compostos mais relevantes de cada classe em um amplo universo amostral, para em uma segunda etapa refinar as pesquisas com as classes de contaminantes mais preocupantes e os locais mais impactados incluindo inclusive análise em sedimentos. ${ }^{171} \mathrm{E}$, finalmente, em uma terceira etapa realizar avaliações de efeitos e biodisponibilidade dos contaminantes emergentes nos locais mais críticos. Isso porque há pouca informação sobre a presença dos contaminantes emergentes nos corpos d'água da Nova Zelândia e, portanto, essa foi a maneira escolhida no país para iniciar as pesquisas nesse universo tão abrangente de compostos e matrizes ambientais.

No Brasil, não há registros de programas oficiais voltados para a problemática dos contaminantes emergentes, muito embora as discussões nos diferentes setores da sociedade têm aumentado significativamente nos últimos anos e as pesquisas acadêmicas têm contribuído expressivamente, fornecendo inúmeros subsídios para tomadas de decisões, o que tem despertado o interesse de reguladores, empresas de saneamento, órgãos governamentais e a população em geral.

Em 2010, a Companhia Ambiental do Estado de São Paulo (CETESB) disponibilizou o Relatório Final da Proposta para Derivatização de Critérios para Contaminantes Ambientais da Agricultura no qual foram identificados os principais praguicidas usados nas lavouras paulistas através de dados fornecidos pelo Instituto de Economia Agrícola. ${ }^{172} \mathrm{~A}$ cana-de-açúcar foi selecionada como a cultura representativa do Estado de São Paulo, dada a imensa área cultivada (24\% da área agrícola na safra 2008/2009), a quantidade de praguicidas empregada na lavoura (63 princípios ativos, dos quais 49 são de ação herbicida) e o crescimento do mercado. Dos praguicidas empregados no cultivo da cana-de-açúcar, a CETESB priorizou 23 herbicidas, dos quais apenas sete são legislados pela Portaria MS 2914/2011 que trata da potabilidade da água. A partir deste levantamento, foram derivados critérios para os 17 herbicidas não legislados na água para consumo humano. ${ }^{173} \mathrm{~A}$ derivação de um critério consiste na avaliação dos dados ecotoxicológicos de uma dada substancia obtidos por estudos epidemiológicos e cenários de exposição (agudo, crônico, efeitos genotóxicos ou teratogêncios, entre outros) que gera um valor máximo permitido que garanta a qualidade da água para os seus usos pretendidos. ${ }^{174}$

A Câmara Técnica de Saúde Pública da Associação Brasileira de Engenharia Sanitária e Ambiental (ABES) publicou em 2012 o Guia de potabilidade para substancias químicas, no qual apresentou critérios de potabilidade para 72 compostos considerados prioritários para o Estado de São Paulo com base em uso e ocorrência. Neste trabalho está apresentado um fluxograma de ações integradas entre saúde e meio ambiente que poderiam ser aplicadas quando forem detectadas, na água de abastecimento público, substancias químicas que podem oferecer riscos à saúde humana, de forma a garantir a qualidade da água que é servida à população. ${ }^{175}$

Os critérios derivados pela CETESB e pela ABES estabeleceram valores apenas para água destinada ao consumo humano. Consequentemente, estes critérios não consideram os efeitos relacionados à exposição de organismos aquáticos não alvos expostos cronicamente a esses contaminantes. Assim, a preservação da vida aquática, e a qualidade da água para fins de dessedentação, irrigação e recreação não necessariamente estão assegurados por esses valores. No Brasil a Resolução CONAMA 357/2005 estabelece valores para os diferentes usos pretendidos da água. Em alguns casos os valores derivados poderiam ser cerca de mil vezes menores dependendo da margem de segurança estabelecida para cada uso.

A legislação brasileira ainda é deficitária em seus critérios de qualidade. Dentre os milhares de compostos consideradas contaminantes emergentes, apenas cerca de 30 pesticidas estão contemplados Portaria MS 2914/2011 e/ou nas Resoluções CONAMA $357 / 2005$ e 396/2008, que tratam da qualidade das águas superficiais e subterrâneas, respectivamente. Isso representa aproximadamente $7 \%$ de todos os pesticidas autorizados para uso no Brasil ( 380$)$, que é o maior consumidor de pesticidas do mundo. Além disso, os valores máximos estabelecidos não consideram os efeitos estrogênicos dos contaminantes que, se assim considerados, poderiam gerar valores máximos seguros até mil vezes menores que os valores atuais vigentes.

\section{O ASPECTO ANALÍTICO E OS BIOENSAIOS}

Os avanços nas pesquisas relacionadas aos contaminantes emergentes está intimamente atrelado ao avanço tecnológico da instrumentação analítica. Muitos contaminantes, seus subprodutos e metabólitos estão presentes no ambiente em concentrações na ordem

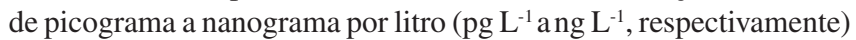
e requerem métodos analíticos com limites de detecção muito baixos para que sejam detectados. De fato, as ferramentas analíticas foram aperfeiçoadas ao longo do tempo e se tornaram cada vez mais sensíveis e seletivas, propriedades imprescindíveis para possibilitar a detecção de compostos a níveis traços em matrizes complexas como são as amostras ambientais, nas quais há impurezas e interferentes em concentrações possivelmente mais altas que as dos próprios contaminantes emergentes. $\mathrm{O}$ aprimoramento analítico permitiu a determinação tanto de novos contaminantes, quanto de contaminantes que provavelmente já estavam presentes no ambiente, mas os métodos analíticos não tinham detectabilidade suficiente para determiná-los. É 
o caso dos hormônios femininos, que sempre foram excretados pela urina das mulheres e, portanto, enriquecem os esgotos diariamente, mas necessitava-se de métodos analíticos com detectabilidade adequada para quantificá-los.

Inicialmente foi preciso saber como quantificar esses contaminantes em concentrações traços empregando o parque instrumental que havia disponível. Para tal, foram publicados por diferentes grupos de pesquisa em todo mundo, diversos trabalhos descrevendo métodos analíticos utilizando GC-MS, ,4,11,23,58-60,176,177 GC-ECD, ${ }^{3,30}$ HPLC-DAD, ${ }^{31,42,48,50,63,67,73,178,179}$ ou HPLC-FL. ${ }^{14,21,42,74,78,180}$ Nas Tabelas 1 e 1 S estão apresentadas as técnicas analíticas empregadas para a determinação dos contaminantes emergentes no Brasil. Com o avanço da espectrometria de massas sequencial e seu acoplamento com cromatografia líquida, o LC/MS ${ }^{1,15,181,182}$ e o LC-MS/MS, , $7,8,12,13,18,29,183,184^{2}$ juntamente com o CG-MS/MS, ${ }^{36,185,186}$ consolidaram-se como as melhores ferramentas analíticas para a determinação dos contaminantes emergentes em concentrações traços.

As técnicas de preparo de amostras também acompanharam esse desenvolvimento analítico e possibilitaram atingir altos fatores de concentração dos analitos. A extração em fase sólida (SPE, do inglês, Solid Phase Extraction) é uma das técnicas mais utilizadas. Trata-se de uma técnica que desloca os compostos das matrizes aquosas para solventes orgânicos utilizando volumes menores de solvente quando comparada à extração líquido-líquido, além de conferir seletividade à extração de classes de compostos de interesse devido à grande variedade de fases extratoras (sorventes) comercializados atualmente. ${ }^{187}$ Mais recentemente, com a possibilidade de se fazer a extração em linha com a determinação por LC-MS/MS, técnica denominada SPE on line, houve uma redução significativa no tempo de análise e quantidade de solventes empregados no preparo de amostras. ${ }^{28,188,189}$ Além da SPE, outras técnicas de preparo de amostras também são utilizadas para a determinação de micropoluentes no ambiente, por exemplo, a microextração em fase sólida (SPME), que faz uso de uma fibra de material sorvente para a extração dos compostos por imersão ou por headspace; a QuECheRS (do inglês, Quick, Easy, Cheap, Effective, Ruged and Safe), que utiliza como etapa inicial a extração por um solvente (originalmente acetonitrila), em seguida adição de sais e separação de fase, etapa de limpeza (clean up) e adição de padrão interno para posterior determinação dos analitos; dentre outras técnicas. ${ }^{190-193}$

Concomitantemente com a otimização das técnicas analíticas, foram desenvolvidos e aprimorados diferentes bioensaios (os quais utilizam organismos vivos para avaliar um efeito de uma substância ao qual foram expostos por um período conhecido de tempo) como ferramentas capazes de fornecer informações adicionais aos ensaios ecotoxicológicos, sobre os efeitos estrogênicos, androgênicos, de sinergismo ou influências antiestrogênicas relacionadas à presença de inúmeros contaminantes em uma amostra complexa.

Os testes de toxicidade empregam métodos padronizados que podem utilizar organismos ou uma população de organismos cultivados em laboratório, ou que sejam representativos de um ambiente, bem como partes de um organismo como culturas de células ou DNA, para avaliar um efeito após a exposição a concentrações/doses conhecidas dos contaminantes. Os efeitos observados (ou end points) podem ser morte, imobilidade, inibição da respiração ou do crescimento, interferência na reprodução, deformidades, genotoxicidade, mutagenicidade, indução de tumores, interferência endócrina, etc.

Os bioensaios in vitro (os quais utilizam culturas celulares) apesar de serem bastante específicos, veem se mostrando uma ferramenta analítica bastante sensível e não seletiva que pode ser usada para complementar a interpretação dos dados químicos obtidos em estudos de ocorrência, como uma análise preliminar de uma avaliação de risco, identificação de cenários mais críticos de contaminação, entre outros. Esses bioensaios podem empregar diferentes mecanismos de detecção incluindo: proliferação de células; LBA (do inglês, Ligand Binding Assay); indução de vitelogenina, proteína produzida no fígado de peixe fêmea em resposta aos estrógenos, que pode ser extraída do plasma e quantificada (a produção de vitelogenina em organismos machos é um indicativo de interferência endócrina que tem sido explorado em diversos estudos); $;^{70,123,141,148}$ indução de luciferase (termo genérico empregado para diferentes enzimas oxidativas que produzem bioluminescência durante a reação enzimática) e interações antígeno-anticorpo como os bioensaios YES (do inglês, Yeast Estrogen Screen), ${ }^{194}$ BLYES (do inglês, BioLuminesce Yeast Estrogen Screening), CALUX (do inglês, Chemical Activated LUciferase gene eXpression). ${ }^{123}$

O bioensaio denominado YES, desenvolvido por Routledge e Sumpter em 1996, ${ }^{194}$ vem sendo largamente utilizado para a avaliação da atividade estrogênica ${ }^{195}$ de amostras ambientais tais como efluentes de ETE, ${ }^{196-199}$ águas superficiais ${ }^{9,51,93,200}$ e água tratada, ${ }^{19,20}$ bem como para avaliar a eficiência de diferentes tipos de tratamento de efluentes. ${ }^{196,201-203}$

No Brasil, Sanchez confirmou a indução de vitelogenina por E2 e EE2 em peixes machos (Rhamdia quelen) nativos da região do Paraná. ${ }^{204}$ Bergamasco e colaboradores reportaram a maior sensibilidade do bioensaio BLYES quando comparada às análises químicas por LC-MS/MS ao estudar quatro diferentes mananciais (Represa de Tanque Grande, Rio Atibaia, Rio Sorocaba e Rio Cotia) no Estado de São Paulo. ${ }^{9}$ Dias e colaboradores avaliaram a atividade estrogênica dos rios Paraíba do Sul e Guandu, no Estado do Rio de Janeiro usando YES como bioensaio e reportaram a preocupação com o potencial estrogênico superior a $1 \mathrm{ng} \mathrm{L}^{-1} \mathrm{em}$ vários pontos ao longo dos rios. ${ }^{196}$

Resumidamente, enquanto os métodos analíticos oferecem os números ou o estoque dos contaminantes nas diferentes matrizes ambientais, os bioensaios usam uma resposta biológica para mensurar alguns efeitos relacionados à presença dos contaminantes e, por serem menos seletivos e mais baratos, podem ser usados para obter um screening inicial do estágio de contaminação. No entanto, o maior desafio está em se obter ferramentas capazes de mensurar concentrações abaixo das quais são observados os efeitos provocados pela presença destes contaminantes. Ao propor um critério de gestão de qualidade da água para a preservação da vida aquática, por exemplo, são necessários métodos analíticos que possuem detectabilidade suficiente para quantificar concentrações dos contaminantes menores que os PNEC calculados. Para o 17 $\alpha$-etinilestradiol, que é um dos estrógenos sintéticos mais potentes amplamente usados nas pílulas anticoncepcionais, o PNEC calculado foi de $0,35 \mathrm{ng} \mathrm{L}^{-1}$ para águas superficiais, ${ }^{205}$ sendo esta uma detectabilidade muito difícil de atingir, o que inviabiliza um monitoramento efetivo e, consequentemente, a inserção deste contaminante em qualquer regulamentação.

\section{DESAFIOS E TENDÊNCIAS}

O cenário brasileiro nos mostrou um avanço nas pesquisas relacionadas aos contaminantes emergentes nos últimos anos, porém ainda é importante destacar que, apesar de poucos trabalhos descritos na literatura, considerando a grandeza territorial e as diferenças socioeconômicas do país, foi possível quantificar contaminantes de preocupação emergente em todas as matrizes aquáticas, inclusive na água tratada, o que nos remete a fragilidade do saneamento básico e aos elevados índices de consumo do país. O desafio da ciência neste cenário se antecede aos processos regulatórios, de forma a investir na garantia da qualidade dos corpos d'água e entender os riscos associados aos padrões de vida modernos e as consequências deste, para a saúde do ambiente que nos cerca. 
A busca por ferramentas analíticas cada vez mais sensíveis para se determinar compostos conhecidos em níveis menores que nanograma por litro, ou ainda compostos que ainda não são conhecidos (do inglês, non-target compounds), como são os casos dos inúmeros produtos de degradação e metabólitos, impulsionam as pesquisas no mundo todo. Por outro lado, os estudos ecotoxicológicos buscam respostas para os efeitos observados, de forma a entender os mecanismos de ação e propor valores que asseguram a qualidade de vida dos organismos. Os avanços no entendimento das questões relacionadas a tantos "novos" contaminantes se deu justamente pela interação entre diferentes áreas das ciências, como a química e a biologia de tal forma a compreender os números (ou concentrações mensuradas) e os efeitos observados, possibilitando propor contaminantes prioritários do ponto de vista ambiental e de saúde pública, subsidiando assim, futuras tomadas de decisões envolvendo os processos regulatórios em vários países, os quais poderão servir de exemplo para o Brasil. Além disso, os estudos envolvendo as tecnologias de tratamentos complementares aos convencionais, empregando novos materiais e sistemas sequenciais, buscam oferecer o que há de mais eficiente na remoção dos contaminantes orgânicos e a minimização da formação dos produtos de transformação, originados após os tratamentos, especialmente a cloração, empregada em praticamente todos os tratamentos como uma etapa final de desinfecção.

\section{CONCLUSÃO}

A temática dos contaminantes emergentes está muito bem representada pelo chamado "Efeito Iceberg". No submerso, são muitos compostos diferentes (tanto de origem antrópica como de ocorrência natural) presentes em baixas concentrações, sendo que poucos deles ocorrem em concentrações maiores que microgramas por litro. A toxicidade pode ser potencializada ou minimizada pela mistura de vários compostos em amostras complexas, como são as amostras ambientais. Os riscos relacionados à exposição crônica são inferidos com estudos ecotoxicológicos que avaliam diferentes endpoints, principalmente quando se pretende avaliar os efeitos causados pelos compostos interferentes endócrinos. Os compostos legislados são, portanto, representados como a ponta deste iceberg, como o que se tem conhecido, sendo que o monitoramento e a fiscalização são os maiores desafios para se manter a qualidade das águas e garantir a saúde da biota e do homem. No entanto, a ciência hoje nos apresenta subsídios suficientes para acreditar que as discussões envolvendo a qualidade das nossas águas está diante de um novo paradigma que precisa ser conhecido para se melhor discutido e, finalmente, assegurar a qualidade de vida das gerações futuras.

\section{MATERIAL SUPLEMENTAR}

A Tabela 1S do Material Suplementar apresenta detalhes de cada trabalho inserido na revisão da literatura incluindo as faixas de concentrações dos contaminantes nas diferentes matrizes, o método analítico utilizado para a determinação, os limites de detecção e quantificação, e o período em que as amostras foram coletadas.

\section{AGRADECIMENTOS}

Os autores agradecem à FAPESP (Auxílio à Pesquisa 2014/247406) e ao Instituto Nacional de Ciencias e Tecnologias Analíticas Avançadas INCTAA (FAPESP, proc. 2008/57808-1 e CNPq proc. 573894/2008-6) pelos auxílios concedidos. À Mayra Guerra e Marina Goularte Pimpim pelo apoio nas revisões bibliográficas. À Mayra Guerra, Diego Campaci de Andrade e Iveraldo Rodrigues pelo auxílio no graphical abstract.

\section{REFERÊNCIAS}

1. Richardson, S. D.; Kimura, S. Y.; Anal. Chem. 2016, 88, 546.

2. Lanchote, V.; Bonato, P.; Water Air Soil Pollut. 2000, 118, 329.

3. Stumpf, M.; Haberer, K.; Rodrigues, S. V.; Baumann, W.; J. Braz. Chem. Soc. 1997, 8, 509.

4. Stumpf M.; Ternes T. A.; Wilken R. D.; Rodrigues S. V.; Baumann W.; Sci. Total Environ. 1999, 225, 135.

5. Ternes, T.; Stumpf, M.; Mueller, J.; Haberer, K.; Wilken, R.; Servos, M.; Sci. Total Environ. 1999, 225, 81.

6. INCTAA; Cafeína em águas de abastecimento no Brasil; Canela, M. C.; Jardim, W. F.; Sodré, F. F.; Grassi, M. T., eds.; Cubo: São Carlos, 2014, cap. 1.5.

7. Machado, K. C.; Grassi, M. T.; Vidal, C.; Pescara, I. C.; Jardim, W. F.; Fernandes, A. N.; Sodré, F. F.; Almeida, F. V.; Santana, J. S.; Canela, M. C.; Nunes, C. R. O.; Bichinho, K. M.; Severo, F. J. R.; Sci. Total Environ. 2016, 572, 138.

8. Ferreira, A. P.; Acta Sci. Technol. 2013, 35, 307.

9. Di Dea Bergamasco, A. M.; Eldridge, M.; Sanseverino, J.; Sodré, F. F.; Montagner, C. C.; Pescara, I. C.; Jardim, W. F.; Umbuzeiro, G. D. A.; J. Environ. Monit. 2011, 13, 3288.

10. De Paiva Pessoa, G.; Dos Santos, A. B.; De Souza, N. C.; Alves, J. A. C.; Do Nascimento, R. F.; Quim. Nova 2012, 35, 968.

11. Pessoa, G. P.; de Souza, N. C.; Vidal, C. B.; Alves, J. A. C.; Firmino, P. I. M.; Nascimento, R. F.; dos Santos, A. B.; Sci. Total Environ. 2014, 490, 288.

12. Queiroz, F. B.; Silva, J. C.; Aquino, S. F.; Coutrim, M. X.; Afonso, R. J. C. F.; J. Braz. Chem. Soc. 2014, 25, 298.

13. Queiroz, F. B.; Brandt, E. M. F.; Aquino, S. F.; Chernicharo, C. A. L.; Afonso, R. J. C. F.; Water Sci. Technol. 2012, 66, 2562.

14. Martins, A. F.; Vasconcelos, T. G.; Henriques, D. M.; Frank, C. da S.; König, A.; Kümmerer, K.; Clean: Soil, Air, Water 2008, 36, 264.

15. Maldaner, A. O.; Schmidt, L. L.; Locatelli, M. A. F.; Jardim, W. F.; Sodré, F. F.; Almeida, F. V.; Pereira, C. E. B.; Silva, C. M.; J. Braz. Chem. Soc. 2012, 23, 861.

16. Reemtsma, T.; Weiss, S.; Mueller, J.; Petrovic, M.; González, S.; Barcelo, D.; Ventura, F.; Knepper, T. P.; Environ. Sci. Technol. 2006, 40, 5451.

17. Luo, Y.; Guo, W.; Ngo, H. H.; Nghiem, L. D.; Hai, F. I.; Zhang, J.; Liang, S.; Wang, X. C.; Sci. Total Environ. 2014, 473-474, 619.

18. Torres, N. H.; Aguiar, M. M.; Ferreira, L. F. R.; Américo, J. H. P.; Machado, Â. M.; Cavalcanti, E. B.; Tornisielo, V. L.; Environ. Monit. Assess. 2015, 187, 379.

19. Solano, M. de L. M.; Montagner, C. C.; Vaccari, C.; Jardim, W. F.; Anselmo-Franci, J. A.; Carolino, R. de O. G.; Luvizutto, J. F.; Umbuzeiro, G. de A.; de Camargo, J. L.; Endocr. Disruptors 2015, 3, e983384.

20. Jardim, W. F.; Montagner, C. C.; Pescara, I. C.; Umbuzeiro, G. A.; Di Dea Bergamasco, A. M.; Eldridge, M. L.; Sodré, F. F.; Sep. Purif. Technol. 2012, 84, 3.

21. Lopes, L. G.; Marchi, M. R. R.; Souza, J. B. G.; Moura, J. A.; Lorenzon, C. S.; Cruz, C.; Amaral, L. A.; Quim. Nova 2010, 33, 639.

22. Melo, S. M.; Brito, N. M.; Water Air Soil Pollut. 2014, 225.

23. Sodré, F. F.; Locatelli, M. A. F.; Jardim, W. F.; Water Air Soil Pollut. 2010, 206, 57.

24. Caldas, S. S.; Bolzan, C. M.; Guilherme, J. R.; Silveira, M. A. K.; Escarrone, A. L. V.; Primel, E. G.; Environ. Sci. Pollut. Res. 2013, 20, 5855 .

25. da Silva, C. P.; Emídio, E. S.; de Marchi, M. R. R.; Environ. Sci. Pollut. Res. 2015, 22, 19706.

26. Campestrini, I.; Jardim, W. F.; Sci. Total Environ. 2017, 576, 374.

27. Souza, R. R.; Martins, E. A. J.; Otomo, J. I.; Furusawa, H. A.; Pires, M. A. F.; Quim. Nova 2012, 35, 627. 
28. Schwanz, T. G.; Llorca, M.; Farré, M.; Barceló, D.; Sci. Total Environ. 2016, 539, 143.

29. Montagner, C. C.; Vidal, C.; Acayaba, R. D.; Jardim, W. F.; Jardim, I. C. S. F.; Umbuzeiro, G. A.; Anal. Methods 2014, 6, 6668.

30. Rissato, S. R.; Libânio, M.; Giafferis, G. P.; Gerenutti, M.; Quim. Nova 2004, 27, 739 .

31. Delmonico, E. L.; Bertozzi, J.; Souza, N. E. de; Oliveira, C. C.; Acta Sci. Technol. 2014, 36, 513.

32. http://dwi.defra.gov.uk/research/completed-research/reports/ DWI70_2_266.pdf, acessada em Dezembro de 2016.

33. Stackelberg, P. E.; Gibs, J.; Furlong, E. T.; Meyer, M. T.; Zaugg, S. D.; Lippincott, R. L.; Sci. Total Environ. 2007, 377, 255.

34. Brandt, E. M. F.; de Queiroz, F. B.; Afonso, R. J. C. F.; Aquino, S. F.; Chernicharo, C. A. L.; J. Environ. Manage. 2013, 128, 718.

35. Aquino, S. F. de; Brandt, E. M. F.; Chernicharo, C. A. de L.; Eng. Sanit. Ambient. 2013, 18, 187.

36. Westerhoff, P.; Yoon, Y.; Snyder, S.; Wert, E.; Environ. Sci. Technol. 2005, 39, 6649 .

37. Petrie, B.; Barden, R.; Kasprzyk-Hordern, B.; Water Res. 2014, 72, 3.

38. Pereira, R. O.; Postigo, C.; de Alda, M. L.; Daniel, L. A.; Barceló, D.; Chemosphere 2011, 82, 789.

39. Hespanhol, I.; Revista do Departamento de Aguas e Esgotos 2015, 63.

40. Campanha, M. B.; Awan, A. T.; de Sousa, D. N. R.; Grosseli, G. M.; Mozeto, A. A.; Fadini, P. S.; Environ. Sci. Pollut. Res. 2015, 22, 7936.

41. de Sousa, D. N. R.; Mozeto, A. A.; Carneiro, R. L.; Fadini, P. S.; Sci. Total Environ. 2014, 484, 19.

42. Montagner, C. C.; Jardim, W. F.; J. Braz. Chem. Soc. 2011, 22, 1452.

43. Locatelli, M. A. F.; Sodré, F. F.; Jardim, W. F.; Arch. Environ. Contam. Toxicol. 2011, 60, 385.

44. Lopes, V. S. A.; Riente, R. R.; da Silva, A. A.; Torquilho, D. F.; Carreira, R. da S.; Marques, M. R. da C.; Mar. Pollut. Bull. 2016, 110, 572.

45. Thomas, K. V.; Araújo da Silva, F. M.; Langford, K. H.; de Souza, A. D. L.; Nizzeto, L.; Waichman, A. V.; J. Am. Water Resour. Assoc. 2014, 50, 302.

46. López-Doval, J. C.; Montagner, C. C.; de Alburquerque, A. F.; MoschiniCarlos, V.; Umbuzeiro, G. A.; Pompêo, M.; Sci. Total Environ. 2017, $575,1307$.

47. Montagner, C. C.; Jardim, W. F.; Von der Ohe, P. C.; Umbuzeiro, G. A.; Environ. Sci. Pollut. Res. 2014, 21, 1850.

48. Froehner, S.; Souza, D. B.; MacHado, K. S.; Da Rosa, E. C.; Water Air Soil Pollut. 2010, 210, 33.

49. Ferreira, A. P.; Cadernos de Saúde Pública 2005, 21, 1884.

50. Bueno-Krawczyk, A. C. D.; Guiloski, I. C.; Piancini, L. D. S.; Azevedo, J. C.; Ramsdorf, W. A.; Ide, A. H.; Guimarães, A. T. B.; Cestari, M. M.; Silva de Assis, H. C.; Chemosphere 2015, 135, 257.

51. Sodré, F. F.; Pescara, I. C.; Montagner, C. C.; Jardim, W. F.; Microchem. J. 2010, 96, 92 .

52. Moreira, D. S.; Aquino, S. F.; Afonso, R. J. C. F.; Santos, E. P. P. C.; de Pádua, V. L.; Environ. Technol. 2009, 30, 1041.

53. Moreira, M.; Aquino, S.; Coutrim, M.; Silva, J.; Afonso, R.; Environ. Technol. 2011, 32, 1409.

54. Machado, K. S.; Cardoso, F. D.; Azevedo, J. C. R.; Braga, C. B.; Acta Sci. Technol. 2014, 36, 421 .

55. Rissato, S. R.; Galhiane, M. S.; Ximenes, V. F.; de Andrade, R. M. B.; Talamoni, J. L. B.; Libânio, M.; de Almeida, M. V.; Apon, B. M.; Cavalari, A. A.; Chemosphere 2006, 65, 1949.

56. Dores, E. F. G. C.; Navickiene, S.; Cunha, M. L. F.; Carbo, L.; Ribeiro, M. L.; De-Lamonica-Freire, E. M.; J. Braz. Chem. Soc. 2006, 17, 866.

57. Dores, E. F. G. C.; Carbo, L.; Ribeiro, M. L.; De-Lamonica-Freire, E. M.; J. Chromatogr. Sci. 2008, 46, 585.

58. Moreira, J. C.; Peres, F.; Simões, A. C.; Pignati, W. A.; Dores, E. D. C.; Vieira, S. N.; Strüssmann, C.; Mott, T.; Ciência \& Saúde Coletiva 2012, 17,1557 .
59. Nogueira, E. N.; Dores, E. F. G. C.; Pinto, A. A.; Amorim, R. S. S.; Ribeiro, M. L.; Lourencetti, C.; J. Braz. Chem. Soc. 2012, 23, 1476.

60. Casara, K. P.; Vecchiato, A. B.; Lourencetti, C.; Pinto, A. A.; Dores, E. F. G. C.; J. Braz. Chem. Soc. 2012, 23, 1719.

61. Jacomini, A. E.; de Camargo, P. B.; Avelar, W. E. P.; Bonato, P. S.; J. Braz. Chem. Soc. 2009, 20, 107.

62. Jacomini, A. E.; De Camargo, P. B.; Avelar, W. E. P.; Bonato, P. S.; Arch. Environ. Contam. Toxicol. 2011, 60, 452.

63. Armas, E. D. De; Teresa, R.; Monteiro, R.; Antunes, P. M.; Alice, M.; Firme, P.; Quim. Nova 2007, 30, 1119.

64. Cappelini, L. T. D.; Cordeiro, D.; Brondi, S. H. G.; Prieto, K. R.; Vieira, E. M.; Environ. Technol. 2012, 3330, 1.

65. Cunha, D. G. F.; Grull, D.; Damato, M.; Blum, J. R. C.; Eiger, S.; Lutti, J. E. I.; Mancuso, P. C. S.; An. Acad. Bras. Cienc. 2011, 83, 1465.

66. de Figueiredo, L.; Chiavelli, L.; da Costa, W.; Anal. Lett. 2013, 46, 1597.

67. Primel, E. G.; Milani, M. R.; Demoliner, A.; Niencheski, L. F. H.; Escarrone, A. L. V.; Int. J. Environ. Anal. Chem. 2010, 90, 1048.

68. Azevedo, D. A.; Silva, T. R.; Knoppers, B. A.; Schulz-Bull, D.; J. Braz. Chem. Soc. 2010, 21, 1096.

69. Albuquerque, A. F.; Ribeiro, J. S.; Kummrow, F.; Nogueira, A. J. A.; Montagner, C. C.; Umbuzeiro, G. A.; Environ. Sci. Process. Impacts 2016, 18,779 .

70. Bila, D. M.; Dezotti, M.; Quim. Nova 2003, 26, 523.

71. Boger, B.; Tonin, F. S.; Guillermo, P.; Zamora, P.; Wagner, R.; Gomes, E. C.; Cienc. Nat. (St. Maria, Braz.) 2015, 37, 725.

72. Quadra, G. R.; Oliveira de Souza, H.; Costa, R. D. S.; Fernandez, M. A. D. S.; Environ. Sci. Pollut. Res. 2016, 1.

73. Carbo, L.; Souza, V.; Dores, E. F. G. C.; Ribeiro, M. L.; J. Braz. Chem. Soc. 2008, 19, 1111.

74. Olivo, V. E.; Tansini, A.; Carasek, F.; Cordenuzzi, D.; Fernandes, S.; Fiori, M. A.; Fragoso, A.; Dal Magro, J.; Rev. Ambient. Água 2015, 10, 445

75. https://www.icict.fiocruz.br/sites/www.icict.fiocruz.br/files/IBAMA_ boletim\%20de\%20comercializacao_2000_2012.pdf, acessada em Junho de 2017.

76. Gotvajn, A. Z.; Zagorc-Koncan, J.; Tisler, T.; Water Sci. Technol. 2001, $44,87$.

77. Albanis, T. A.; Hela, D. G.; Sakellarides, T. M.; Konstantinou, I. K.; J. Chromatogr. A 1998, 823, 59.

78. Ribeiro, M. L.; Lourencetti, C.; Pereira, S. Y.; de Marchi, M. R. R.; Quim. Nova 2007, 30, 688 .

79. http://www.dnpm.gov.br/assuntos/ao-publico/paginas/explorar-aguamineral-veja-como-e-facil, acessada em Junho de 2017.

80. http://www.dnpm.gov.br/dnpm/sumarios/agua-mineral-sumariomineral-2014, acessada em Junho de 2017.

81. Vidal, C.; Jardim, W.F.; Resumos do IV Encontro Nacional de Química Ambiental, Aracaju, Brasil, 2008.

82. Ghiselli, G.; Jardim, W. F.; Quim. Nova 2007, 30, 695.

83. http://www.ibge.gov.br/home/estatistica/populacao/censo2010/default_ atlas.shtm, acessado em Junho de 2017.

84. Majewsky, M.; Cavalcanti, C. B. G.; Cavalcanti, C. P.; Horn, H.; Frimmel, F. H.; Abbt-Braun, G.; Environ. Earth Sci. 2014, 72, 4891.

85. http://brazilianpharmasolutions.com.br/wp-content/uploads/2015/02/ Panorama-Mercado-Farmac\%C3\%AAutico_final_final.pdf, acessada em Junho de 2017.

86. Keith, L. H.; Life Sci. 1976, 19, 1631.

87. Hignite, C.; Azarnoff, D. L.; Life Sci. 1977, $20,337$.

88. http://www.who.int/mediacentre/factsheets/fs194/en/, acessada em Junho de 2017.

89. Gardinali, P. R.; Zhao, X.; Environ. Int. 2002, 28, 521.

90. Chen, Z.; Pavelic, P.; Dillon, P.; Naidu, R.; Water Res. 2002, 36, 4830.

91. Daneshvar, A.; Aboulfadl, K.; Viglino, L.; Broséus, R.; Sauvé, S.; Madoux-Humery, A. S.; Weyhenmeyer, G. A.; Prévost, M.; Chemosphere 2012, 88, 131. 
92. Glassmeyer, S.; Furlong, E. T.; Kolpin, D. W.; Cahill, J. D.; Zaugg, S D.; Werner, S. L.; Meyer, M. T.; Kryak, D. D.; Environ. Sci. Technol. 2005, 39, 5157.

93. Montagner, C. C.; Umbuzeiro, G. A.; Pasquini, C.; Jardim, W. F.; Environ. Sci. Process. Impacts 2014, 16, 10.

94. Kasprzyk-Hordern, B.; Dinsdale, R. M.; Guwy, A. J.; J. Chromatogr. A 2007, 1161, 132

95. Kasprzyk-Hordern, B.; Dinsdale, R. M.; Guwy, A. J.; Water Res. 2008, 42, 3498.

96. Mastroianni, N.; Postigo, C.; De Alda, M. L.; Barcelo, D.; J. Chromatogr. A 2013, 1322, 29.

97. Huerta-Fontela, M.; Galceran, M. T.; Ventura, F.; Anal. Chem. 2007, 79, 3821.

98. Feitosa, R. S.; Sodré, F. F.; Maldaner, A. O.; Quim. Nova 2013, 36, 291.

99. Pereira, C. D. S.; Maranho, L. A.; Cortez, F. S.; Pusceddu, F. H.; Santos, A. R.; Ribeiro, D. A.; Cesar, A.; Guimarães, L. L.; Sci. Total Environ. 2016, 548-549, 148

100. Rosa Boleda, M.; Huerta-Fontela, M.; Ventura, F.; Galceran, M. T.; Chemosphere 2011, 84, 1601.

101. http://www.unodc.org/wdr2015/, acessada em Junho de 2017.

102. http://repository.tudelft.nl/islandora/object/uuid:dff3e7ed-8b81-4fefae45-6f2be270d89e?collection=research, acessada em Junho de 2017.

103. Serôdio, P.; Nogueira, J. M. F.; Water Res. 2006, 40, 2572.

104. http://www.ibama.gov.br/phocadownload/qualidadeambiental/relatorios/ produtos_agrotoxicos_comercializados_brasil_2009.pdf, acessada em Junho de 2017.

105. http://www.who.int/ipcs/publications/en/toc.pdf, acessada em Junho de 2017.

106. http://www.acpo.org.br/biblioteca/03_interferentes_hormonais/epa.pdf, acessada em Junho de 2017.

107. Liu, Z. hua; Kanjo, Y.; Mizutani, S.; Water Res. 2010, 44, 567.

108. Mnif, W.; Hassine, A. I. H.; Bouaziz, A.; Bartegi, A.; Thomas, O.; Roig, B.; Int. J. Environ. Res. Public Health 2011, 8, 2265.

109. Goloubkova, T.; Spritzer, P. M.; Arq. Bras. Endocrinol. Metabol. 2000, $44,323$.

110. Dodds, E. C.; Lswaon, W.; Nature 1936, 137, 996.

111. Schueler, F. W.; Science 1946, 103, 221.

112. Sluczewski, A.; Roth, P.; Gynecol. Obstet. 1948, 47, 164.

113. Carson, R. Primavera Silenciosa; $2^{\text {a }}$ ed., Edições Melhoramentos: São Paulo, 1962.

114. Stumm-Zollinger, E.; Fair, G. M.; J. - Water Pollut. Control Fed. 1965, $37,1506$.

115. Tabak, H. H.; Bunch, R. L.; Dev. Ind. Microbiol. 1970, 11, 367.

116. Desbrow, C.; Routledge, E. J.; Brighty, G. C.; Sumpter, J. P.; Waldock, M.; Environ. Sci. Technol. 1998, 32, 1549.

117. Purdom, C. E.; Hardiman, P. A.; Bye, V. V. J.; Eno, N. C.; Tyler, C. R.; Sumpter, J. P.; Chem. Ecol. 1994, 8, 275.

118. Kolpin, D. W.; Furlong, E. T.; Meyer, M. T.; Thurman, E. M.; Zaugg, S. D.; Barber, L. B.; Buxton, H. T.; Environ. Sci. Technol. 2002, 36, 1202.

119. Halling-Sorensen, B.; Nielsen, S. N.; Lanzky, P. F.; Ingerslev, F.; Holten Lützhøft, H. C.; Jørgensen, S. E.; Chemosphere 1998, 36, 357.

120. Daughton, C. G.; Ternes, T. A.; Environ. Health Perspect. 1999, 107, 907.

121. Harrison, P. T. C.; Holmes, P.; Humfrey, C. D. N.; Sci. Total Environ. 1997, 205, 97.

122. Lintelmann, J.; Katayama, A.; Kurihara, N.; Shore, L.; Wenzel, A.; Pure Appl. Chem. 2003, 75, 631.

123. Campbell, C. G.; Borglin, S. E.; Green, F. B.; Grayson, A.; Wozei, E.; Stringfellow, W. T.; Chemosphere 2006, 65, 1265.

124. Shanle, E. K.; Xu, W.; Chem. Res. Toxicol. 2011, 24, 6.

125. Daston, G. P.; Gooch, J. W.; Breslin, W. J.; Shuey, D. L.; Nikiforov, A. I.; Fico, T. A.; Gorsuch, J. W.; Reprod. Toxicol. 1997, 11, 465.

126. Sumpter, J. P.; Johnson, A. C.; Environ. Sci. Technol. 2005, 39, 4321.
127. http://www.cdc.gov/des/consumers/index.html, acessada em Junho de 2017.

128. Herman-Giddens, M. E.; Journal of Adolescent Health 2007, 40, 201.

129. Tanner, J. M.; Nature 1973, 243, 95.

130. Weber, R. F. A.; Pierik, F. H.; Dohle, G. R.; Burdorf, A.; BJU Int. 2002, $89,143$.

131. Toppari, J.; Larsen, J. C.; Christiansen, P.; Giwercman, A.; Grandjean, P.; Guillette, L. J.; Jégou, B.; Jensen, T. K.; Jouannet, P.; Keiding, N.; Leffers, H.; McLachlan, J. A.; Meyer, O.; Müller, J.; Rajpert-De Meyts, E.; Scheike, T.; Sharpe, R.; Sumpter, J.; Skakkebaek, N. E.; Environ. Health Perspect. 1996, 104, 741.

132. Sharpe, R. M.; Skakkebaek, N. E.; Lancet 1993, 341, 1392.

133. Wolff, M. S.; Toniolo, P. G.; Lee, E. W.; Rivera, M.; Dubin, N.; J. Natl. Cancer Inst. 1993, 85, 648.

134. Reaves, D. K.; Ginsburg, E.; Bang, J. J.; Fleming, J. M.; Endocr. Relat. Cancer 2015, 22, 69.

135. De Cock, M.; Van de Bor, M.; Environ. Int. 2014, 70, 15.

136. Warner, M.; Wesselink, A.; Harley, K. G.; Bradman, A.; Kogut, K.; Eskenazi, B.; Am. J. Epidemiol. 2014, 179, 1312.

137. Miodovnik, A.; Engel, S. M.; Zhu, C.; Ye, X.; Soorya, L. V.; Silva, M. J.; Calafat, A. M.; Wolff, M. S.; Neurotoxicology 2011, 32, 261.

138. Wan, Y.; Choi, K.; Kim, S.; Ji, K.; Chang, H.; Wiseman, S.; Jones, P. D.; Khim, J. S.; Park, S.; Park, J.; Lam, M. H. W.; Giesy, J. P.; Environ. Sci. Technol. 2010, 44, 5233.

139. Singh, S.; Li, S. S. L.; Genomics 2011, 97, 148.

140. Milla, S.; Depiereux, S.; Kestemont, P.; Ecotoxicology 2011, 20, 305.

141. Filby, A. L.; Shears, J. A.; Drage, B. E.; Churchley, J. H.; Tyler, C. R.; Environ. Sci. Technol. 2010, 44, 4348.

142. Brian, J. V.; Harris, C. A.; Scholze, M.; Kortenkamp, A.; Booy, P.; Lamoree, M.; Pojana, G.; Jonkers, N.; Marcomini, A.; Sumpter, J. P.; Environ. Sci. Technol. 2007, 41, 337.

143. Kidd, K. A.; Blanchfield, P. J.; Mills, K. H.; Palace, V. P.; Evans, R. E.; Lazorchak, J. M.; Flick, R. W.; Proc. Natl. Acad. Sci. U. S. A. 2007, 104, 8897.

144. Maurício, R.; Diniz, M.; Petrovic, M.; Amaral, L.; Peres, I.; Barceló, D.; Santana, F.; Environ. Monit. Assess. 2006, 118, 75.

145. Pait, A. S.; Nelson, J. O.; Aquat. Toxicol. 2003, 64, 331.

146. Diniz, M. S.; Peres, I.; Magalhães-Antoine, I.; Falla, J.; Pihan, J. C.; Ecotoxicol. Environ. Saf. 2005, 62, 427.

147. Salo, H. M.; Hébert, N.; Dautremepuits, C.; Cejka, P.; Cyr, D. G.; Fournier, M.; Aquat. Toxicol. 2007, 84, 406.

148. Christiansen, L. B.; Pedersen, K. L.; Pedersen, S. N.; Korsgaard, B.; Bjerregaard, P.; Environ. Toxicol. Chem. 2000, 19, 1867.

149. Volkova, K.; Reyhanian Caspillo, N.; Porseryd, T.; Hallgren, S.; Dinnétz, P.; Porsch-Hällström, I.; Horm. Behav. 2015, 73, 30.

150. Hayes, T. B.; Khoury, V.; Narayan, A.; Nazir, M.; Park, A.; Brown, T.; Adame, L.; Chan, E.; Buchholz, D.; Stueve, T.; Gallipeau, S.; Proc. Natl. Acad. Sci. U. S. A. 2010, 107, 4612.

151. Matthiessen, P.; Integr. Environ. Assess. Manage. 2008, 4, 274.

152. Oehlmann, J.; Di Benedetto, P.; Tillmann, M.; Duft, M.; Oetken, M.; Schulte-Oehlmann, U.; Ecotoxicology 2007, 16, 29.

153. Park, B. J.; Kidd, K.; Environ. Toxicol. Chem. 2005, 24, 2027.

154. Oehlmann, J.; Schulte-Oehlmann, U.; Tillmann, M.; Markert, B.; Ecotoxicology 2000, 9, 383

155. Parks, L. G.; LeBlanc, G. A.; Aquat. Toxicol. 1996, 34, 291.

156. Oberdörster, E.; Rittschof, D.; LeBlanc, G. A.; Arch. Environ. Contam. Toxicol. 1998, 34, 21.

157. Wollenberger, L. Tese de Doutorado, Technical University of Denmark, Dinamarca, 2005

158. Pickering, A. D.; Sumpter, J. P.; Environ. Sci. Technol. 2003, 37, 331A.

159. Oaks, J. L.; Gilbert, M.; Virani, M. Z.; Watson, R. T.; Meteyer, C. U.; Rideout, B. a; Shivaprasad, H. L.; Ahmed, S.; Chaudhry, M. J. I.; Arshad, M.; Mahmood, S.; Ali, A.; Khan, A. A.; Nature 2004, 427, 630. 
160. Gotardo, A. T.; Pavanelli, E. L.; Carvalho, H. F.; Lemes, K. M.; Arruda, R. P.; Kempinas, W. G.; Górniak, S. L.; Small Rumin. Res. 2014, 119, 81.

161. https://www.epa.gov/sites/production/files/2015-02/documents/ epa815f15001.pdf, acessada em Junho de 2017.

162. https://www.epa.gov/endocrine-disruption/overview-first-list-chemicalstier-1-screening-under-endocrine-disruptor, acessada em Junho de 2017.

163. https://www.epa.gov/endocrine-disruption/endocrine-disruptorscreening-program-tier-1-screening-determinations-and, acessada em Junho de 2017.

164. https://www.epa.gov/sites/production/files/2015-08/documents/1.pdf, acessada em Junho de 2017.

165. http://ec.europa.eu/health/scientific_committees/environmental_risks/ opinions/sctee/sct_out73_en.htm, acessada em Junho de 2017.

166. http://eur-lex.europa.eu/LexUriServ/LexUriServ.do?uri=OJ:L:2009:20 1:0036:0038:EN:PDF, acessada em Junho de 2017.

167. Coquery, M.; Morin, A.; Bécue, A.; Lepot, B.; TrAC - Trends Anal. Chem. 2005, 24, 117.

168. http://ec.europa.eu/environment/archives/docum/pdf/bkh_main.pdf, acessada em Junho de 2017.

169. http://ec.europa.eu/environment/chemicals/endocrine/pdf/sota_edc_ final_report.pdf, acessada em Junho de 2017.

170. von der Ohe, P. C.; Dulio, V.; Slobodnik, J.; De Deckere, E.; Kühne, R.; Ebert, R. U.; Ginebreda, A.; De Cooman, W.; Schüürmann, G.; Brack, W.; Sci. Total Environ. 2011, 409, 2064.

171. http://www.aucklandcouncil.govt.nz/SiteCollectionDocuments/ aboutcouncil/planspoliciespublications/technicalpublications/tr201600 6updateonemergingorganiccontaminantsnewzealand.pdf, acessada em Junho de 2017

172. http://www.iea.sp.gov.br/out/index.php, acessada em Junho de 2017.

173.http://laboratorios.cetesb.sp.gov.br/wp-content/uploads/ sites/47/2013/11/2010-Proposta-Derivacao-Agricultura.pdf, acessada em Junho de 2017.

174. Umbuzeiro, G. D. A.; Kummrow, F.; Rei, F. F. C.; InterfacEHS 2010, 5, 1.

175. ABES; Guia de potabilidade para substâncias químicas; Umbuzeiro, G. de A., coord.; Editora Limiar: São Paulo, 144 p.

176. Pietrogrande, M. C.; Basaglia, G.; TrAC, Trends Anal. Chem. 2007, 26, 1086.

177. Kot-Wasik, A.; Debska, J.; Namie nik, J.; TrAC, Trends Anal. Chem. 2007, 26, 557.

178. Ribeiro, C.; Pardal, M. Â.; Martinho, F.; Margalho, R.; Tiritan, M. E.; Rocha, E.; Rocha, M. J.; Environ. Monit. Assess. 2009, 149, 183.

179. Alda, M. J. L. de; Barceló, D.; J. Chromatogr. A 2000, 892, 391.

180. Snyder, S. A.; Keith, T. L.; Verbrugge, D. A.; Snyder, E. M.; Gross, T. S.; Kannan, K.; Giesy, J. P.; Environ. Sci. Technol. 1999, 33, 2814.

181. Petrović, M.; Hernando, M. D.; Díaz-Cruz, M. S.; Barceló, D.; J. Chromatogr. A 2005, 1067, 1.
182. Richardson, S. D.; Anal. Chem. 2004, 76, 3337.

183. Robles-Molina, J.; Lara-Ortega, F. J.; Gilbert-López, B.; García-Reyes, J. F.; Molina-Díaz, A.; J. Chromatogr. A 2014, 1350, 30.

184. Moschet, C.; Wittmer, I.; Simovic, J.; Junghans, M.; Piazzoli, A.; Singer, H.; Stamm, C.; Leu, C.; Hollender, J.; Environ. Sci. Technol. 2014, 48, 5423.

185. Kong, L.; Kadokami, K.; Wang, S.; Duong, H. T.; Chau, H. T. C.; Chemosphere 2015, 122, 125.

186. Fromme, H.; Küchler, T.; Otto, T.; Pilz, K.; Müller, J.; Wenzel, A.; Water Res. 2002, 36, 1429.

187. Richardson, S. D.; Ternes, T. A.; Anal. Chem. 2014, 86, 2813.

188. Togola, A.; Baran, N.; Coureau, C.; Anal. Bioanal. Chem. 2014, 406, 1181 .

189. Huntscha, S.; Singer, H. P.; McArdell, C. S.; Frank, C. E.; Hollender, J.; J. Chromatogr. A 2012, 1268, 74.

190. Lima Gomes, P. C. F.; Barnes, B. B.; Santos-Neto, Á. J.; Lancas, F. M.; Snow, N. H.; J. Chromatogr. A 2013, 1299, 126.

191. Mühlen, C. von; Lanças, F. M.; Sci. Chromatogr. 2014, 6, 117.

192. Martins, G. L.; Friggi, C. A.; Prestes, O. D.; Vicari, M. C.; Friggi, D. A.; Adaime, M. B.; Zanella, R.; Clean - Soil, Air, Water 2014, 42, 1441.

193. Franco, M. S. Tese de Doutorado, Universidade de São Paulo, Brasil, 2015.

194. Routledge, E. J.; Sumpter, J. P.; Environ. Toxicol. Chem. 1996, 15, 241.

195. Eldridge, M.; Sanseverino, J.; Umbuzeiro, G. D. A.; Sayler, G. S.; Environ. Monit. 2011, 528.

196. Dias, A. C. V.; Gomes, F. W.; Bila, D. M.; Sant'Anna, G. L.; Dezotti, M.; Ecotoxicol. Environ. Saf. 2015, 120, 41.

197. Metcalfe, C. D.; Kleywegt, S.; Letcher, R. J.; Topp, E.; Wagh, P.; Trudeau, V. L.; Moon, T. W.; Sci. Total Environ. 2013, 454-455, 132.

198. Shappell, N. W.; Billey, L. O.; Forbes, D.; Matheny, T. A.; Poach, M. E.; Reddy, G. B.; Hunt, P. G.; Environ. Sci. Technol. 2007, 41, 444.

199. Salste, L.; Leskinen, P.; Virta, M.; Kronberg, L.; Sci. Total Environ. 2007, 378, 343.

200. Vethaak, A. D.; Lahr, J.; Schrap, S. M.; Belfroid, A. C.; Rijs, G. B. J.; Gerritsen, A.; De Boer, J.; Bulder, A. S.; Grinwis, G. C. M.; Kuiper, R. V.; Legler, J.; Murk, T. A. J.; Peijnenburg, W.; Verhaar, H. J. M.; De Voogt, P.; Chemosphere 2005, 59, 511.

201. Caliman, F. A.; Gavrilescu, M.; Clean - Soil, Air, Water 2009, 37, 277.

202. Rosenfeldt, E. J.; Chen, P. J.; Kullman, S.; Linden, K. G.; Sci. Total Environ. 2007, 377, 105.

203. Chen, M.; Ohman, K.; Metcalfe, C.; Ikonomou, M. G.; Amatya, P. L.; Wilson, J.; Water Qual. Res. J. Can. 2006, 41, 351.

204. Sanchez, D. C. O.; Dissertação de Mestrado, Universidade Federal do Paraná, Brasil, 2006.

205. Caldwell, D. J.; Mastrocco, F.; Hutchinson, T. H.; Länge, R.; Heijerick, D.; Janssen, C.; Anderson, P. D.; Sumpter, J. P.; Environ. Sci. Technol. 2008, 42, 7046. 